\title{
Role of cholesterol metabolism in the anticancer pharmacology of selective estrogen receptor modulators
}

Diego Gómez-Coronado a,b, Miguel A. Lasunción ${ }^{\mathrm{a}, \mathrm{b}}$, Javier Martínez-Botas ${ }^{\mathrm{a}, \mathrm{b}}$, María E. Fernández-Suárez ${ }^{\mathrm{c}}$

a Servicio de Bioquímica-Investigación, Hospital Universitario Ramón y Cajal, IRYCIS, Ctra. de Colmenar, km 9, 28034 Madrid, Spain.

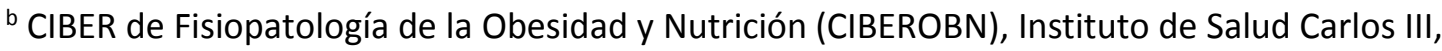
Spain.

' Department of Pharmacology, University of Oxford, Mansfield Road, Oxford, OX1 3QT, United Kingdom.

Corresponding author: Diego Gómez-Coronado, Servicio de Bioquímica-Investigación, Hospital Universitario Ramón y Cajal, IRYCIS, Ctra. de Colmenar, km 9, 28034 Madrid, Spain.

E-mail: diego.gomez@hrc.es

Phone +34913368684

E-mails of coauthors:

María E. Fernández-Suárez: maria.fernandez-suarez@pharm.ox.ac.uk

Javier Martínez-Botas: javier.botas@hrc.es

Miguel A. Lasunción: miguel.a.lasuncion@hrc.es

\section{Abstract}

Selective estrogen receptor modulators (SERMs) are a class of compounds that bind to estrogen receptors (ERs) and possess estrogen agonist or antagonist actions in different tissues. As such, they are widely used drugs. For instance, tamoxifen, the most prescribed SERM, is used to treat ER $\alpha$-positive breast cancer. Aside from their therapeutic targets, SERMs have the capacity to broadly affect cellular cholesterol metabolism and handling, mainly through ER-independent mechanisms. Cholesterol metabolism reprogramming is crucial to meet the needs of cancer cells, and different key processes involved in cholesterol homeostasis have been associated with cancer progression. Therefore, the effects of SERMs on cholesterol homeostasis may be relevant to carcinogenesis, either by contributing to the anticancer efficacy of these compounds or, conversely, by promoting resistance to treatment. Understanding these aspects of SERMs actions could help to design more efficacious therapies. Herein we review the effects of SERMs on cellular cholesterol metabolism and handling and discuss their potential in anticancer pharmacology.

Keywords: Selective estrogen receptor modulators, cholesterol metabolism, intracellular cholesterol trafficking, cancer, cell proliferation.

\section{Abbreviations}

ACAT, acyl-coenzyme A:cholesterol acyltransferase; AEBS, anti-estrogen binding site; $B C$, breast cancer; $C A D$, cationic amphiphilic drug; $C E$, cholesteryl ester; $D D A$, dendrogenin A; EMT, epithelial to mesenchymal transition; ER, estrogen receptor; LE/L, late endosomes/lysosomes; HUVEC, human umbilical vein endothelial cells; LDLR, LDL receptor; NPC, Niemann-Pick type C; OCDO, 6-oxo-cholestan-3 $\beta, 5 \alpha$-diol; SERM, selective estrogen receptor modulator; TAM, tumorassociated macrophage; $27 \mathrm{HC}, 27$-hydroxycholesterol. 


\section{Introduction}

Selective estrogen receptor modulators (SERMs) are a diverse class of compounds that bind to estrogen receptors (ERs) and induce a unique receptor conformation that results in a specific effect in estrogen-responsive tissues. By interacting with ERs, SERMs exert effects that fall into a spectrum between full agonist and full antagonist activity in a tissue-specific manner. This peculiarity depends on several factors, including differential expression of the ER subtypes ( $\alpha$ and $\beta$ ) and ligand-dependent receptor conformational changes that condition the interaction with coactivators and corepressors which, in turn, are differentially expressed in different tissues [1-3]. SERMs are primarily used to treat different conditions related to women's pathophysiology [3-6]. The first three SERMs approved for clinical practice were tamoxifen, toremifene and raloxifene. Tamoxifen, the pioneering SERM, is a triphenylethylene derivative used for the treatment of ER $\alpha$-positive breast cancer (BC), and is the standard of care for premenopausal patients and for risk reduction in both premenopausal and postmenopausal women. Toremifene, which differs from tamoxifen only by the presence of a chlorine atom in the ethyl chain, is indicated for the treatment of advanced BC. Raloxifene, a benzothiophene derivative, is used for the treatment and prevention of osteoporosis, and in the United States, it is also used for risk reduction of BC in postmenopausal women. Approximately $75 \%$ of women diagnosed with early stage $B C$ have $E R \alpha$-positive disease. Although the importance of $E R \alpha$ in $B C$ development is well established, the role of ER $\beta$ is unclear, despite its presence in mammary tumors $[7,8]$.

Tamoxifen, the most frequently used SERM, acts as an ER antagonist in breast tissue, yet as a partial agonist in other tissues such as the endometrium and bone [3-6]. The in vivo efficacy of tamoxifen is attributed to its active metabolites, 4-hydroxytamoxifen and 4-hydroxy- $\mathrm{N}$ desmethyl-tamoxifen (endoxifen), both being products of cytochrome P450 enzymes (CYP2D6, CYP3A and CYP2C). Endoxifen is found at much higher concentrations than 4-hydroxytamoxifen, and is thus considered the most important tamoxifen metabolite $[9,10]$. However, a large proportion of patients shows de novo or acquired resistance to tamoxifen treatment $[6,11]$.

Aside from its ER-mediated effects, at pharmacologically relevant concentrations, tamoxifen displays multiple ER-independent actions that may also be involved in its anticancer effects $[12,13]$, such as, for example, the inhibition of protein kinase $C$ signaling [14-17]. These offtarget effects may explain that $5-10 \%$ of ER-negative tumors are sensitive to tamoxifen treatment [18], and have led to clinical trials of tamoxifen for non-BC [12]. Tamoxifen and other SERMs have been shown to alter different cellular processes relevant to cholesterol homeostasis through ER-dependent or -independent mechanisms. This has an impact at the systemic level, as SERMs consistently reduce circulating concentrations of total and lowdensity lipoprotein (LDL) cholesterol in women, which, by analogy with the effect of estrogens, is usually attributed to ER agonism in the liver [1,5]. However, although some studies have reported an increase in high-density lipoprotein (HDL) cholesterol by SERM treatment [19-23], these drugs very often do not change this variable [1,5], and one study in tamoxifen-treated men found a decrease in HDL-cholesterol [24]. Furthermore, SERMs can increase plasma triacylglycerols [25,26], occasionally causing severe hypertriglyceridemia [27].

Cholesterol is a critical component of cell membranes, in that it is required for membrane biogenesis and intracellular signaling cascades initiated in lipid rafts. Added to its toxicity when cholesterol is in excess, its cellular concentrations are tightly controlled $[28,29]$. Tumor cells demand high amounts of cholesterol for proliferation, which can be satisfied by increasing 
both cholesterol biosynthesis and LDL uptake through the LDL receptor (LDLR) [30-32]. Internalized LDL is degraded in late endosomes/lysosomes (LE/L) to release free cholesterol, which leaves these organelles. Moreover, proliferating cells reduce the removal [33] and increase the storage of cholesterol [34]. The expression of cholesterol biosynthesis enzymes and the LDLR is mainly controlled by sterol regulatory element-binding protein (SREBP) 2 , an integral endoplasmic reticulum membrane protein that, upon cholesterol depletion, is transported, escorted by the SREBP-cleavage activating protein (SCAP), to the Golgi, where SREBP-2 is activated to subsequently stimulate the transcription of target genes [35,36]. Another isoform, SREBP-1c, activates genes for fatty acid biosynthesis, whereas SREBP-1a stimulates the biosynthesis of both cholesterol and fatty acids. When sufficient cholesterol levels are reached in the endoplasmic reticulum SCAP prevents the transport and activation of SREBP-2. Moreover, the phosphatidylinositol 3-kinase (PI3K)/AKT/mammalian target of rapamycin complex 1 (mTORC1) axis stimulates the SREBP pathway in response to energy levels, growth factors and nutrients [36]. Excess cholesterol is esterified by acyl-coenzyme A:cholesterol acyltransferase, or sterol O-acyltransferase (ACAT/SOAT) 1. Cholesteryl esters are incorporated into cytoplasmic lipid droplets, a form of cholesterol storage until it is used following cholesterol ester hydrolysis. On the other hand, cholesterol excess is sensed by the liver $X$ receptors (LXR) $\alpha$ and $\beta$, which are nuclear receptors activated by certain oxysterols, ultimately leading to increased cellular cholesterol efflux to HDL and decreased cholesterol uptake [37]. This is accomplished by stimulating the transcription of membrane cholesterol transporters, such as the ATP-binding cassette transporter (ABC) A1 and ABCG1, and that of the inducible degrader of the LDLR (IDOL), respectively. The cholesterol derivative 27-hydroxycholesterol is an LXR ligand that, interestingly, has also been recognized as an endogenous SERM and cancer promoter (see section 3.6.2).

The first indication of cholesterol involvement in cancer was the finding that prostate adenomas and other tumor tissues had increased cholesterol content compared to normal tissues [38-40]. In fact, intratumoral cholesterol synthesis, measured through squalene epoxidase (SQLE) expression in prostate biopsies, has been shown to be a marker of poor prognosis in prostate cancer [41], which is in accordance with the reprogramming of lipid metabolism, including cholesterol metabolism, in cancer cells in order to fuel rapid proliferation $[30,42,43]$. Innumerable epidemiological studies have been conducted to establish the relationship between cancer incidence and mortality with serum cholesterol levels, dietary cholesterol intake and treatment with hypocholesterolemic drugs, as well as experimental studies to understand the biochemical bases of that relationship. The first prospective studies arose from the suspicion that there was a correlation between mortality rates from colon cancer and coronary heart disease, with dietary cholesterol as a common etiological factor [44]. Surprisingly, it was found that men developing colon or lung cancer had initial serum cholesterol levels that were significantly lower than those non-affected [44-49]. Subsequent studies, however, concluded that low cholesterol levels were a consequence of tumour activity rather than a predisposing factor [47,50-52]. A paradigmatic case is leukemia, where serum cholesterol levels are substantially reduced [53-55]. Later prospective studies in the general population found a positive correlation between serum cholesterol levels and the incidence of prostatic cancer [56,57], but discrepant results were observed for other cancers [58]. These differences among cancer sites and the influence of sex, dietary habits and cancer stage [59-62] have made it difficult to generalize the impact of cholesterol homeostasis in cancer.

The effects of hypolipidemic drugs, mostly statins, have been extensively studied in both humans and experimental models. In this regard, it is important to distinguish between early and late stages of cancer progression. The largest retrospective studies showed no influence of 
statins on the incidence of breast [63-65], prostate [66], lung [67,68] and colorectal [69] cancers. On the other hand, most studies concurred that statins reduce the recurrence and mortality from all-site cancer [70,71], particularly in breast [72,73], prostate [74], lung [75] and colorectal cancers [76], supporting that statins impact tumor progression rather than early carcinogenesis [77]. Cholesterol homeostasis is influenced by lifestyle factors, mainly diet and exercise, which are considered to be associated with cancer development [78]. Although data on dietary cholesterol intake and cancer risk are not unanimous, many studies indicate that a high cholesterol intake is linked to increased risk of several types of cancer, including BC $[60,79,80]$. Physical activity is inversely associated and sedentary behaviour is positively associated with an elevated risk of cancer [78].

Aside from its requirement for cell proliferation, several mechanisms have been proposed to explain the possible role of cholesterol in cancer. Among them, a role has been attributed to bile acids, which derive from cholesterol and undergo biotransformation to secondary bile acids by gut microbiota [81]. Secondary bile acids, especially deoxycholic acid, are potential causative agents of cancers of the digestive system [81,82]. On the other hand, cholesterol and cholesterol-derived oxysterols affect the immune response in the tumor microenvironment [83] (see below). Therefore, multiple connections exist between cholesterol metabolism and relevant processes in cancer progression. In this context, the effects of SERMs on cholesterol metabolism and homeostasis may be relevant, either by contributing to their anti-tumoral effects or, on the contrary, by inducing resistance to treatment. In this review, we summarize the effects of SERMs on cellular cholesterol metabolism and handling and discuss their impact, often scarcely examined, on the anticancer pharmacology of SERMs.

\section{Role of cholesterol in cell proliferation and differentiation}

Mammalian cells require cholesterol for cell proliferation and there is a striking dependence of cell cycle progression on cholesterol availability $[84,85]$. Cholesterol has the structural features to optimally support the growth of mammalian cells. These features include a $3 \beta$-hydroxyl group, a trans A/B ring system and a $\Delta^{5}$-double bond [86]. Of note, desmosterol, the immediate precursor of cholesterol in the Bloch pathway (Fig. 1), is as suitable as cholesterol for cell proliferation $[87,88]$, as they share these structural characteristics. It has been proposed that, for proliferation, cholesterol exerts two functions: a structural or bulk function related to membrane formation that can be satisfied by diverse sterols, and a much more specific, regulatory function, which involves cell cycle kinases [86,89-91].

Proliferating cells express both a high rate of cholesterol synthesis, with increased HMG-CoA reductase (HMGCR) activity, and elevated LDLR activity [30-32]. Indeed, cancer cells harboring mutant p53 have increased transcription of SREBP-modulated genes [92-95]. Cells with dysfunctional LDLR depend on endogenous cholesterol synthesis to satisfy their need to proliferate [96,97]. Experimentally, in cells incubated in medium free of cholesterol, inhibition of cholesterol biosynthesis unfailingly leads to cell proliferation abrogation, but the cell cycle may be affected differently depending on the cell type. Cells harboring wild-type p53 are usually arrested at the G0/G1 phase, as a consequence of the stimulation of $\mathrm{p} 21^{\mathrm{WAF} 1 / \mathrm{CIP} 1}$ and p27 $7^{\mathrm{Kip} 1}$ and subsequent inactivation of different cyclin-dependent kinases [98-102], whereas promyelocytic HL-60 and lymphoblastic MOLT-4 cells, with null and mutant-inactive p53, respectively, do transit through $S$ phase and accumulate at G2/M $[86,103,104]$, showing decreased expression of cyclin B1 and Cdk1-Cyclin B activity $[90,103]$ and are unable to complete cytokinesis [105]. Supplementation of the culture medium with LDL or free cholesterol dissolved in ethanol, but not other sterols, prevented all these effects, showing the 
requirement of cholesterol for cytokinesis [86,103-105]. This is in line with the accumulation of cholesterol in the scission furrow during mitosis [106] and the activation of cholesterol biosynthesis during the $\mathrm{G} 2 / \mathrm{M}$ phase $[107,108]$.

HL-60 cells grown in a cholesterol-free medium have a cell cholesterol content of approximately $5-6 \mu \mathrm{g} / \mathrm{mg}$ of cell protein [104]. When cells are treated with inhibitors of postlanosterol enzymes, they may complete the first division, but in the next cycle they are arrested at G2/M because the cholesterol content of daughter cells falls below the threshold level ( $2.5 \mu \mathrm{g} / \mathrm{mg}$ cell protein) [104]. Several inhibitors may exert these effects, including SKF104976, AY9944 and SR31747; however, the more upstream the affected enzyme, the more severe the effect [104]. A similar pattern was observed in colorectal cancer cells treated with TASIN compounds, which inhibit $3 \beta$-hydroxysteroid- $\Delta^{8}, \Delta^{7}$-isomerase (D8D7I/EBP), 7-dehydrocholesterol reductase (DHCR7) and 3 $\beta$-hydroxysterol- $\Delta^{24}$-reductase (DHCR24) (Fig. 1): cell viability was reduced only when D8D7I was affected [109]. These cell proliferation findings parallel the severity of post-lanosterol congenital defects, where for a similar affectation in cholesterol availability, the symptoms depend on which step in the pathway is altered (and which sterol is accumulated): the earlier, the more severe [110-112]. As the effects of cholesterol synthesis inhibition were mitigated by LDL or free cholesterol, it is tempting to conclude that cholesterol depletion was the sole cause of cell proliferation inhibition; however, a contribution of intermediate sterols accumulation cannot be ruled out.

The effects of HMGCR inhibition have been extensively studied and the results demonstrated that, in addition to cholesterol, mevalonic acid or its non-sterol isoprenoid derivatives are also needed for cell division [113-115]. In human leukemia cells incubated in a medium free of cholesterol and mevalonic acid, the effects of statins on cell viability and cell cycle distribution greatly depend on the dose used. With supratherapeutic doses ( $\geq 50 \mu \mathrm{M}$ lovastatin), which blocked both cholesterol biosynthesis and protein prenylation [103], massive apoptosis occurred and the proportion of cells accumulating in G0/G1 highly increased to the detriment of the active $S$ and $G 2 / M$ phases $[101,103,116,117]$. This effect was independent of p53 status as the addition of exogenous mevalonate prompted cells arrested at $\mathrm{G} 1$ to progress through the $S$ phase and reach G2/M [103]. This is in accordance with the increase in protein prenylation during early-to-mid G1 [118-120]. With lower lovastatin doses, which only suppressed cholesterol biosynthesis, cells accumulated preferentially in G2/M phase, an effect that was both prevented and reversed by cholesterol supply [103]. These results demonstrate the distinct roles of mevalonate, or its non-sterol derivatives, and cholesterol in cell cycle progression, the first in G1-to-S transition and the second in mitosis completion. By contrast, inhibition of mevalonate-pyrophosphate decarboxylase (MVD), which acts a few steps downstream of HMGCR, induced DNA damage and the accumulation of cells in the $S$ phase, indicative of replication stress, via dNTP depletion [121]. Given that replication stress is a major source of genomic instability [122,123], the possibility exists that the accumulation of mevalonic acid phosphorylated derivatives induces tumorigenesis.

With regard to SERMs, their effects on cell proliferation have been studied as both ERmodulators and as inhibitors of the cholesterol synthesis pathway. Focusing on this second action, treatment of BC MCF-7 cells with tamoxifen at doses of $1 \mu \mathrm{M}$ or higher was shown to inhibit cell proliferation and arrest the cell cycle at G0/G1 [124]. These effects were accompanied by the accumulation of both zymostenol and 7-dehydrocholesterol. Given that cells were incubated with $5 \%$ serum, it may be that these effects on cell cycle progression were not only due to cholesterol deficiency. Indeed, the provision of zymostenol or 7-dehydrocholesterol to cells not treated with tamoxifen recapitulated the effects of the drug: namely cell proliferation inhibition and cell cycle arrest [124]. These results show that alterations of the intermediate sterols/cholesterol balance may impact cell proliferation. 
The potential of cholesterol synthesis inhibition to reduce cell growth in vivo has also been demonstrated. As circulating LDL is a main source of cholesterol for cells, it is expected that highly proliferative and not sufficiently irrigated cells, such as tumor cells, would be the most affected by cholesterol biosynthesis inhibition, as has been demonstrated for different cancer xenografts in mice. Thus, statins reduced growth and induced apoptosis in many of these models [125-128]. RO 48-8071, which inhibits lanosterol synthesis, selectively suppressed growth of human prostate cancer cells, without signs of toxicity [129]. Ketoconazole, which inhibits lanosterol metabolization, retarded the growth of neuroblastoma [130], glioblastoma [131] and epidermoid carcinoma [132]. Inhibition of DHCR24 by triparanol reduced the growth of lung cancer cells [133], and TASIN-1, by inhibiting D8D7I, suppressed tumor growth of colorectal cancer cells [134].

Most tumors show abnormalities in the differentiation stage of their clonal cell constituents (anaplasia). Induction of a differentiation response in malignant cells, including leukemia cells, may have positive clinical implications, such as the loss of proliferative potential and the induction of apoptosis [135]. The earliest evidence linking cholesterol metabolism to cell differentiation comes from the 1980s. Connor et al. demonstrated that exposure of HL-60 cells to dimethyl sulfoxide, retinoic acid or hypoxanthine rapidly decreased sterol and phospholipid syntheses, long before inhibition of DNA synthesis and signs of myeloid differentiation were observed [136]. These results were in line with previous findings that showed that circulating granulocytes, in contrast to lymphocytes and monocytes, lack SQLE and, moreover, the ability to transform lanosterol into cholesterol $[137,138]$. In line with this, treatment of HL-60 cells with either SKF104976, a specific inhibitor of lanosterol 14 $\alpha$-demethylase (CYP51A1), or zaragozic acid, a potent inhibitor of squalene synthase (FDFT1), was sufficient to differentiate cells following the granulocyte lineage, similar to all-trans retinoic acid [139]. This effect was prevented by the early supply of exogenous cholesterol to cells, suggesting a link to cholesterol depletion [139]. Furthermore, treatment with low concentrations of lovastatin $(<1 \mu \mathrm{M})$ induced granulocytic differentiation of the acute myeloid leukemia cell lines AML-5 and NB-4, as indicated by increased expression of CD11b and CD18 [135].

Cholesterol metabolism appears to be involved in other differentiation processes. In primary avian erythroid progenitor cells, specific inhibition of oxidosqualene cyclase (OSC/LSS) arrested cell self-renewal and triggered differentiation into erythrocytes [140]. In gonads, the changes in sterols composition during both spermatogenesis and oogenesis have been recognized for years. The accumulation of the so-called meiosis activating sterols (MAS) is characteristic: follicular fluid MAS (FF-MAS) and testis MAS (T-MAS), two post-lanosterol precursor sterols in the cholesterol biosynthesis pathway [141-145] (Fig. 1). These changes are due to specific alterations in the activity of certain enzymes involved in cholesterol biosynthesis including CYP51A $[145,146]$. Interestingly, the supply of lanosterol or MASs induced meiosis resumption in oocytes in vitro supporting the hypothesis that MASs play a role in the sequence of proliferative and differentiation phases in oogenesis $[147,148]$. However, the possibility that lanosterol is also active in spermatogenesis cannot be ruled out [144]. Additionally, the accumulation of C8-9 unsaturated sterols, as achieved by inhibition of CYP51, sterol $\Delta^{14}$ reductase (TM7SF2), or D8D7I in the post-lanosterol pathway (Fig. 1), has been demonstrated to induce the formation of oligodendrocytes from oligodendrocyte progenitor cells (OPCs) and to enhance remyelination $[149,150]$. The supply of different MASs was sufficient to differentiate OPCs into mature oligodendrocytes, whereas analogous sterols lacking the C8-9 double bond were ineffective [149]. It is pertinent to mention that both tamoxifen and raloxifene also induced OPC differentiation due to D8D7I inhibition [149]. Moreover, SERMs induce differentiation of MCF-7 BC cells, as indicated by the accumulation and secretion of lipids, and the expression of a milk fat globule protein [124,151,152]. These results underscore the role of intracellular sterol balance in cell fate. 
Taken together, a scheme may be drawn where both stem and cancer cells have active cholesterol metabolism that allows them to proliferate, and modulation of post-lanosterol enzymes resulting in changes in the intermediate sterols/cholesterol ratio contributes to the proliferation/differentiation decision making.

\section{Selective estrogen receptor modulators, cholesterol metabolism and cancer}

\subsection{Cholesterol biosynthesis}

Cholesterol biosynthesis is considered a branch of the mevalonate pathway. A scheme of the whole pathway in mammalian cells starting from acetyl-CoA is shown in Fig. 1 . The synthesis of cholesterol involves more than 30 reactions and more than 20 enzymes. In this pathway, in addition to cholesterol, a number of sterol and non-sterol isoprenoids with biological relevance are also synthesized. Worth mentioning due to their relevance in tumor growth are mevalonate-5-phosphate, which disrupts binding of DnaJ heat shock protein family (Hsp40) member A1 (DNAJA1) to misfolded proteins [93], and farnesyl- and geranylgeranyl pyrophosphate needed for protein prenylation $[92,94]$. The mevalonate pathway is upregulated in cancer cells through p53 mutations and alterations in different signal transduction pathways relevant in cell proliferation, all converging on SREBP $[43,92,153]$. Also illustrating the importance of cholesterol biosynthesis in cancer cells, the upregulation of the enzymes of this pathway was identified as a mechanism of resistance of ER-positive BC cells to estrogen deprivation $[154,155]$. Enzymes involved in this pathway are finely regulated at both the transcriptional and posttranscriptional levels. Among the former, the main, but not only, mechanism is mediated by SREBP-2 in response to cholesterol availability [35,36]. Moreover, the pathway is coordinated with other metabolisms, including fatty acid, glucose and energy metabolisms. As the enzyme giving rise to mevalonate, HMGCR is the rate-limiting step in the route, while OSC/LSS specifically modulates the biosynthesis of sterols. A handful of enzyme inhibitors are available, acting at different steps on the pathway (Fig. 1). Statins, which are widely used, are competitive inhibitors of HMGCR and indirectly reduce plasma cholesterol levels via LDLR upregulation.

Despite the importance of HMGCR for the survival and proliferation of cancer cells, there is controversy about the impact of tumor expression of this enzyme on the clinical outcome. Immunohistochemical studies have found either no association between HMGCR expression and BC outcome $[156,157]$ or a significant association between high HMGCR expression and a better prognosis of breast, ovarian or colorectal cancer [158-161]. However, gene expression studies have found that high HMGCR mRNA levels negatively impact BC prognosis, especially in patients with ER-positive tumors [162,163]. The reason for this discrepancy is unclear, but it has been suggested that the favorable outcome in some immunohistochemical studies was influenced by the specificity of the antibody against HMGCR that was used [162].

It is well known that tamoxifen and other SERMs inhibit cholesterol biosynthesis [164-166], which may contribute to the decrease in serum cholesterol levels when SERMs are used therapeutically $[1,5,165,166]$. This effect is independent of their action on ER [167], but is due to the inhibition of enzymes involved in the post-lanosterol part of the cholesterol biosynthesis pathway. When individual sterols were measured in the sera of women treated with tamoxifen or toremifene, a substantial increase in zymostenol was detected, indicative of the inhibition of D8D7I (EBP) [166]. A milder increase in desmosterol, the immediate precursor of cholesterol through the reaction of DHCR24, was also observed with both SERMs [166]. In cultured cells, similar changes in sterol composition were observed, whose intensity varied depending on the cell type and the rate of cholesterol synthesis. In general, a decrease in the content of cholesterol and the accumulation of zymostenol were detected, in addition to other precursor sterols depending on the SERM and the dose used [149,168-171]. 
Mechanistically, tamoxifen and other SERMs bind with high affinity to the so-called antiestrogen binding site (AEBS), which is a microsomal hetero-oligomeric complex including the cholesterogenic enzymes D8D7I and DHCR7 $[168,172]$. Given that DHCR7 can interact physically and functionally with DHCR24, the possibility exists that DHCR24 also forms part of the AEBS [173]. This is consistent with the fact that 4-OH-tamoxifen, also a high affinity AEBS ligand, caused the accumulation of mostly desmosterol [168]. It has been shown that the accumulation of sterol intermediates leads to the appearance of multilamellar bodies and eventually induce cell death and autophagy $[174,175]$. As further discussed in section 3.6.1, the interaction with the AEBS has been suggested to be relevant for the anti-tumoral efficacy of tamoxifen [152]. D8D7I features a binding site that accommodates multiple different ligands including tamoxifen and other cationic amphiphilic drugs (CADs), whose positively-charged amine group mimics the carbocationic sterol intermediate $[176,177]$. In keeping with this, toremifene inhibits D8D7I, while ospemifene, which differs from toremifene in the absence of the amino group, does not [149]. This mechanism could also explain the broad specificity exhibited by different CADs (i.e. SERMs, antipsychotics, AY9944, U18666A) at inhibiting enzymes that generate carbocationic intermediates in the respective sterol reduction reaction, such as D8D7I, DHCR7, DHCR14 and DHCR24 [178-180].

As a result of cholesterol biosynthesis inhibition by SERMs, activation of SREBP-2 and induction of SRE-containing genes are predictable [35,36,181], as observed for HMGCR $[169,182]$. This response is expected to be ineffective in terms of cholesterol formation as long as the SERM is present in the medium. In fact, stimulation of upstream enzymes expression would further increase the accumulation of SERM-targeted enzyme substrates that may have biological activities $[149,174,175]$. Another gene highly expressed in response to SERMs is $L D L R$, which is consistent with the increase in LDL uptake seen in cells in vitro $[169,182]$.

\subsection{LDL uptake and endolysosomal cholesterol trafficking}

LDL uptake and subsequent endolysosomal degradation constitute the fundamental pathway for exogenous cholesterol supply to cells [183]. Upon its binding to the LDLR at the plasma membrane, LDL is endocytosed, dissociates from the LDLR in acidic endosomes and the receptor is recycled to the plasma membrane. $L D L$ is then delivered to $L E / L$, where its cholesteryl esters are hydrolyzed by lysosomal acid lipase. The free cholesterol generated is exported from LE/L with the participation of the Niemann-Pick type C (NPC) proteins 1 and 2 and it is ultimately transported to two key destinations, the plasma membrane and the endoplasmic reticulum $[184,185]$.

SERMs increase the expression and activity of LDLR, as found in different human cancer cells $[169,182,186]$, primary lymphocytes [182] and rat liver [187]. This effect may contribute to their hypocholesterolemic action in patients (see section 1 ). In cells expressing $E R \alpha$, tamoxifen and $17 \beta$-estradiol enhanced $L D L R$ transcription by inducing the binding of an $E R \alpha / S p 1$ complex to a Sp1-cis-element in the LDLR promoter [186]. However, we have shown that tamoxifen, toremifene, raloxifene and the tamoxifen-active metabolite endoxifen can increase LDLR expression and activity through an ER-independent mechanism: first, the effect on LDLR was observed in MOLT-4 lymphoblastic leukemia cells [169,182], which do not express ERs [188]; second, unlike SERMs, 17ß-estradiol produced no effect in lymphocytes [182]; and third, the anti-estrogen ICl 182,780 did not alter the effect of SERMs [182]. The up-regulation of LDLR was associated with enhanced SREBP-induced transcriptional activity and gene expression, also affecting cholesterogenic and lipogenic genes $[169,182]$. SREBP activation was not just a consequence of the inhibition of cholesterol biosynthesis by SERMs, because the combined treatment with one SERM and lovastatin, a more potent cholesterol biosynthesis inhibitor, produced a synergistic increase in LDLR expression and activity, indicating the involvement of 
different mechanisms of action of both drugs $[169,182]$. Notably, coadministration of raloxifene and simvastatin, another HMGCR inhibitor, to hypercholesterolemic postmenopausal women was superior to monotherapy with either drug in reducing LDLcholesterol concentration [189]. We found that the SERMs interfere with endosomal cholesterol trafficking, resulting in the accumulation of LDL-derived free cholesterol in LE/L in an ER-independent manner $[169,182,190]$. This effect, which was observed in diverse cell lines and primary cells, resembled what occurs in fibroblasts from patients with NPC disease, caused by defective NPC1 or NPC2 proteins [191]. This blockade prevents LDL-derived cholesterol from inhibiting SREBP activation and LDLR expression, and thereby cells continue to take up LDL.

Higher tumor LDLR expression is associated with a worse prognosis in BC patients, including patients undergoing tamoxifen therapy $[192,193]$. Silencing the LDLR in Her2-overexpressing BC cells inhibited tumor growth in mice [192]. Glioblastomas appear to rely primarily on exogenous rather than endogenous cholesterol for growth $[194,195]$. In these tumors, where LDLR is overexpressed relative to normal brain tissue [194,195], a hyperactivated epidermal growth factor receptor/PI3K/AKT pathway is common, thereby promoting SREBP-1 activation and unrestrained LDLR expression [194]. However, the expression of genes for cholesterol biosynthesis was downregulated relative to normal brain, as well as that of genes for the synthesis of oxysterols that are LXR ligands [195]. Targeting the LDLR by treatment with LXR agonists induced IDOL-mediated LDLR degradation and augmented ABCA1 expression, which caused inhibition of tumor growth and increased apoptosis in mouse models $[194,195]$. Tumors of ALK+ anaplastic large cell lymphoma are an extreme case of cholesterol biosynthesis suppression, where the loss of SQLE renders them auxotrophic for cholesterol [196].

Therefore, inhibiting exogenous cholesterol supply, as accomplished through interference with LDL-derived cholesterol trafficking, is conceivably detrimental for tumor growth, and especially for cholesterol auxotrophic tumors.

The mechanism for cholesterol trafficking inhibition caused by tamoxifen, toremifene and raloxifene is not well defined, but it may be secondary to lysosomal trapping of these drugs. Like most SERMs, these drugs are CADs which can enter the lysosome where, by protonation of their amino group at acidic $\mathrm{pH}$, lose their ability to diffuse across the membrane and are confined in this organelle [197]. In agreement with this, tamoxifen inhibits acidification of endosomes and lysosomes [198]. Lysosomal trapping is considered the major cause of CADinduced phospholipidosis [197]. Protonated CADs disrupt the interaction between negatively charged bis(monoacylglycero)phosphate, highly enriched in intralysosomal vesicles, and positively charged phospholipases, such as acid sphingomyelinase, this being released and degraded into the lysosomal lumen. Accumulating sphingomyelin, which has high affinity for cholesterol, is known to inhibit cholesterol transport by NPC2 and, therefore, to trigger accumulation of cholesterol in lysosomes [197]. Moreover, given that several CADs are able to bind to the sterol sensing domain of NPC1, the distortion of NPC1 function by SERMs at the lysosomal membrane cannot be discarded [199-202]. Although the structural requirements for this interaction are not precisely delineated, one study with U18666A, a CAD and prototypical inhibitor of cholesterol trafficking [203], showed that correct positioning of the amino group is necessary [199].

Besides its degradative function, the lysosome is a platform for several homeostatic signaling pathways. This organelle is essential for mTORC1 signaling, which is activated at the lysosomal surface [204]. mTOR is a serine/threonine kinase that coordinates cell growth and division in response to energy levels, growth signals and nutrients, and which, when deregulated, is implicated in cancer $[205,206]$. Importantly, the activation of the PI3K/AKT/mTOR pathway confers treatment resistance in ER-positive BC and correlates with a poorer outcome in patients treated with endocrine therapies, including tamoxifen [6]. In fact, the PI3K/AKT/mTOR 
pathway and downstream effectors can phosphorylate and activate the ER, even in the absence of estrogen $[6,207]$. It has been shown that cholesterol drives lysosomal recruitment and activation of mTORC1, which requires SLC38A9, a lysosomal transmembrane amino acid transporter that contains cholesterol-responsive motifs and which interacts with mTORC1 and NPC1 [208]. Moreover, the oxysterol binding protein-mediated delivery of cholesterol across endoplasmic reticulum-lysosome contacts is essential for mTORC1 activation [209]. SERMs [210] and other inhibitors of endolysosomal cholesterol trafficking $[201,202,211]$ reduce mTORC1 signaling in endothelial cells (HUVEC). In vitro and preclinical studies have found that such compounds also inhibit angiogenesis [201,202,210,212], a process controlled by mTOR signaling and which is essential for tumor growth and metastasis [213]. The anti-angiogenic effect of tamoxifen has been demonstrated in ER-negative animal models [214]. The inhibition of both mTORC1 signaling and angiogenesis is prevented by exogenous cholesterol delivered by cholesterol/methyl- $\beta$-cyclodextrin complexes without affecting the endolysosomal accumulation of cholesterol $[201,202,210]$. Like the CAD-mediated cholesterol trafficking blockade, depletion of cellular cholesterol by methyl- $\beta$-cyclodextrin treatment also abrogates mTORC1 signaling, and addition of LDL or cholesterol/methyl- $\beta$-cyclodextrin restores it [208]. Therefore, depletion of membrane cholesterol by either method impedes mTORC1 activity, likely due to impairment of the functionality and/or stability of different membrane attached molecules required for signaling through the PI3K/AKT/mTORC1 pathway $[205,206]$. Collectively, these observations indicate that cholesterol trafficking has a critical role in cell growth and, particularly, in angiogenesis, making it a promising target against cancer [215].

The SERM-mediated restriction of cholesterol availability through inhibition of both intracellular cholesterol trafficking and biosynthesis could deeply affect tumor growth, potentially contributing to the anticancer effect of SERMs. However, the deprivation of cholesterol caused by SERMs elicits a SREBP-mediated regulatory response aimed to restore cholesterol supply $[169,182]$. As master regulators of lipid biosynthesis and uptake $[35,36]$, SREBPs play a central role in lipid metabolism reprogramming in cancer cells. SREBPs are upregulated in a variety of cancers and mediate the activation of lipid metabolism by oncogenic signaling, like that through the PI3K/AKT/mTORC1 pathway, thus supporting rapid tumor growth [216]. Blocking SREBP/SCAP translocation to the Golgi or suppressing SREBP activating cleavage attenuate the growth of different cancer cells and tumors, which points to the SREBP pathway as an attractive target in cancer treatment [216]. In the face of cellular cholesterol shortage, the SREBP-mediated regulatory response might limit the effect of SERMs. Whether inhibition of the SREBP pathway combined with SERM treatment results in additional antitumor efficacy deserves further research.

\subsection{Cholesterol esterification}

Cholesterol esterification is a mechanism for buffering excess cellular free cholesterol, which is toxic, and stores it for use when needed. Cholesterol esterification is catalyzed by ACAT (SOAT), ACAT1 being expressed in all tissues whereas ACAT2 is localized in hepatocytes and enterocytes [217]. Accumulation of cholesteryl ester (CE) droplets is a hallmark of macrophages and smooth muscle cells in atherosclerotic lesions, and can be induced in vitro by exposing macrophages to acetyl-LDL $[218,219]$. ACAT resides in the endoplasmic reticulum, so that LDL-derived cholesterol must egress from lysosomes to be re-esterified. In cells from NPC patients [220,221] or treated with U18666A [222] the LDL-mediated stimulation of cholesterol esterification is diminished, concomitant with the impairment of the feedback response of LDLR activity and cholesterol biosynthesis. Similarly, tamoxifen, toremifene and raloxifene inhibit ACAT activity $[182,190,223]$, thus suppressing the acetyl-LDL-induced increase of CE levels in macrophages $[190,223]$. Moreover, a direct inhibition of ACAT activity 
by tamoxifen has been found in rat liver microsomal extracts, raloxifene being a weak inhibitor in this system [223].

Cholesterol esterification is deregulated in a variety of cancer cells and tumors, which show CE and lipid droplet accumulation and ACAT1 overexpression [34]. These parameters correlate inversely with survival of patients with glioblastoma [224] or pancreatic cancer [225]. In BC, markers of aggressiveness are higher in CE-rich than CE-poor tumors [226]. Consistently, inhibition of CE accumulation by abrogating ACAT1 activity or expression suppresses the development of glioblastoma, pancreatic and prostate cancer in mice $[224,225,227,228]$. There is a close link between CE accumulation and increased cholesterol supply, mainly through enhancing LDLR expression and LDL uptake [225-227]. The underlying mechanism in prostate and pancreatic cancer has been shown to be the loss of PTEN (phosphatase and tensin homolog) and subsequent stimulation of the PI3K/AKT/mTOR pathway, which results in SREBP activation [225,227]. ACAT1 prevents the subsequent accretion of intracellular free cholesterol and induction of endoplasmic reticulum stress and ultimately apoptosis $[225,229,230]$. These findings imply that targeting cholesterol esterification by inhibiting ACAT1 or cholesterol supply may be beneficial against such tumors. SERMs could be effective in this regard. Nevertheless, there is evidence that CE accumulation is lower in ER-positive than in ER-negative BC tumors [226] and cell lines [231], and that ACAT1 inhibition has less effect on the proliferation of ER-positive cells [231]. Therefore, inhibition of cholesterol esterification may have a poor contribution to the efficacy of ER-positive BC treatment with tamoxifen.

\subsection{Scavenger receptor class B type I (SR-BI)}

$\mathrm{SR}-\mathrm{BI}$ is a membrane protein that mediates the selective delivery of HDL-CE to the liver for cholesterol excretion in the final stage of reverse cholesterol transport, and it is a key determinant of HDL metabolism [232,233]. The human homologue of rodent SR-BI was cloned first and denominated CD36 and LIMPII analogous 1 (CLA-1) [234], and was subsequently shown to exhibit a wide specificity for native and modified lipoproteins [235]. Although highly expressed in liver and steroidogenic tissues, SR-BI displays an ample cell and tissue distribution, and in peripheral tissues is able to mediate the bidirectional flux of cholesterol between cells and HDL $[232,233,235,236]$. Thus, SR-BI can contribute to cholesterol delivery to cells to sustain cell proliferation [237-240] and steroidogenesis [232]. Additionally, upon HDL binding and cholesterol flux, SR-BI can initiate multiple signaling pathways, such as the activation of the oncogenic kinase c-Src, for which the interaction of SR-BI with the scaffold protein PDZK1 is required [241,242].

We have found that tamoxifen or raloxifene treatment of male mice fed a western-type diet enhanced hepatic SR-BI protein expression, but had no effect on mRNA levels. This was associated with decreased serum HDL-cholesterol concentrations and accelerated HDL-CE catabolism [190]. Similar results were obtained in female fasted rats treated with the SERM acolbifene [187]. The mechanism for the increase in liver SR-BI protein expression by SERMs is unknown, but the involvement of an estrogenic effect is unlikely, because $17 \alpha$-ethinyl estradiol inhibited SR-BI expression in rat liver, although stimulated its expression in steroidogenic tissues [236]. Nevertheless, SERMs may not increase SR-BI expression in women's liver, because, as mentioned above, SERMs do not reduce circulating HDL-cholesterol in treated women, but one study in tamoxifen-treated men reported a decrease in HDL-cholesterol [24]. On the other hand, tamoxifen, raloxifene and toremifene did increase SR-BI expression in human monocyte-derived macrophages [190]. 
SR-BI is overexpressed in a range of cancer cells and tumors, and in patients, it is associated with disease aggressiveness and poor prognosis [243-246]. Overall or event-free survival is reduced in BC [247], clear cell renal cell carcinoma [240], lung adenocarcinoma [248] and neuroblastoma [249] expressing high tumor levels of SR-BI. In prostate cancer, while SR-BI levels are associated with higher Gleason grade and poor prognosis, LDLR levels are not [250], thus highlighting the relative importance of SR-BI in certain malignancies. In a mouse xenograft model of prostate cancer, progression to castration-resistance involves the increase of SR-BI protein expression and cholesterol biosynthesis, likely fuelling de novo androgen production [251]. Aside from contributing to cholesterol supply [238,240,252], SR-BI mediates the HDLinduced activation of c-Scr and, subsequently, PI3K/AKT and mitogen activated protein kinase (MAPK) pathways, thereby stimulating proliferation, migration, invasion and protection from apoptosis in cancer cells [237-240,253]. Moreover, the interaction with SR-BI and activation of the PI3K/AKT axis mediates the angiogenic effect of HDL in hypoxia by regulating the hypoxiainducible factor $1 \alpha$ pathway [254]. Remarkably, SR-BI knockdown attenuates the growth of both ER-negative and ER-positive BC cells-derived xenografts in mice [238].

The above evidence supports the notion that SR-BI potentiates cancer progression. If SERMs were able to upregulate SR-BI in cancer cells, as they do in human macrophages and rodent liver $[187,190,255]$, this could, in principle, favor disease progression. In the case of macrophages, increased SR-BI expression could have an immunosuppressive effect. It has been described that macrophage SR-BI has an anti-inflammatory role $[233,246]$ and, on the other hand, tumor-associated macrophages (TAMs) are correlated with cancer aggressiveness and poor prognosis [256]. Therefore, SERM-induced upregulation of macrophage SR-BI could contribute to promote treatment resistance, an issue that remains to be explored.

\subsection{LXR pathway and cholesterol efflux}

LXR $\alpha$ and LXR $\beta$ are pivotal regulators of cholesterol homeostasis that function as transcription factors by heterodimerization with the retinoid $X$ receptor. LXRs are activated by certain cholesterol-derived oxysterols and the cholesterol precursor desmosterol in response to increased cellular sterol content [37]. As a consequence, cholesterol efflux is stimulated through the induction of $A B C A 1$ and $A B C G 1$ expression. $A B C A 1$ transfers cholesterol to lipidfree apolipoprotein $\mathrm{A}-\mathrm{I}$, the major apolipoprotein component of $\mathrm{HDL}$, and small HDL particles, whereas ABCG1 exports cholesterol to larger HDL particles [257]. Moreover, LXRs stimulate the expression of IDOL, an E3 ubiquitin ligase that promotes degradation of the LDLR, and inhibit cholesterol biosynthesis [37]. The most abundant LXR-activating oxysterol is

27-hydroxycholesterol, formed by cholesterol hydroxylation in mitochondria. In dividing cells, the high demand for cholesterol requires concomitant upregulation of the SREBP and downregulation of the LXR transcriptional programs [33]. Thus, LXR agonists suppress cell proliferation, whereas LXR ablation promotes it [33,258-261]. The effect of LXR activation is more pronounced in ER-positive than ER-negative BC cells and is accompanied by inhibition of ER $\alpha$ expression [258].

Tamoxifen, raloxifene and toremifene decrease cholesterol efflux from AcLDL-loaded macrophages to HDL and, especially, to apolipoprotein A-I. This effect is due to impairment of both the induction of $A B C A 1$ and $A B C G 1$ protein expression and the exit of lipoprotein-derived cholesterol from LE/L, while it is ER-independent [190]. The SERMs also decrease ABCA1 gene expression in proliferating cells, such as lymphoblastoma MOLT-4 cells [169]. Concordantly, 
SERMs oppose the LDL- and AcLDL-induced transcriptional activity of LXR in hepatoma HepG2 cells and THP-1 macrophages, respectively (article in preparation). Moreover, tamoxifen or raloxifene administration in mice downregulated liver protein expression of ABCG5 and ABCG8, two LXR targets expressed in hepatocytes and enterocytes that, forming a heterodimer, in hepatocytes pump sterols to the bile duct [190]. Collectively, these results suggest that SERMs, by blocking intracellular cholesterol trafficking, impair the generation of LXR-activating oxysterols from lipoprotein cholesterol and subsequent induction of the expression of $A B C$ transporters. Similarly, cells with defective cholesterol trafficking due to mutant NPC proteins fail to generate oxysterols in response to LDL [262]. The SERM-mediated inhibition of cholesterol biosynthesis also likely contributes to impair the supply of LXR activators.

LXRs are involved in numerous types of cancer, thus arising as potential therapeutic targets [263-265]. LXR expression is positively associated with survival in colorectal [266] and nonsmall-cell lung cancer [267]. Moreover, LXR $\beta$ polymorphisms influence gallbladder cancer risk [268]. Multiple evidence from mouse studies using LXR agonist administration or genetic models show that LXRs inhibit the progression of different types of cancers, including $B C$ $[194,195,259,269-274]$. The tumor suppressor role of LXRs is linked to the stimulation of ABC transporters expression and IDOL-mediated LDLR degradation, thus limiting cholesterol availability for cell proliferation and survival $[194,195]$. Nonetheless, different mechanisms may mediate the anticancer effect of LXRs [263-265]. LXR activation disturbs the activity of the $\mathrm{PI} 3 \mathrm{~K} /$ Akt pathway, at least in part by altering membrane lipid rafts secondary to increased cholesterol efflux [271,275]. Additionally, LXR upregulates the long non-coding RNA LINC01125, which mediates the increase in PTEN, a PI3K/AKT axis inhibitor, and p53 expression [274]. On the other hand, LXR $\alpha$ induces the metabolic deactivation of $17 \beta$-estradiol by stimulating the hepatic expression of estrogen sulfotransferase (Est or Sult1e1), consequently attenuating estrogen-dependent $\mathrm{BC}$ growth in mice [276].

In line with its function as a cholesterol exporter, ABCA1 displays anticancer activity in mice $[277,278]$, and loss-of-function mutations, including somatic mutations present in human tumors, reduce the capacity of ectopically expressed $A B C A 1$ to inhibit the growth of colon cancer xenografts [277]. In keeping with this, decreased ABCA1 expression has been observed in several types of tumors [278-281], and ovarian cancer patients with lower ABCA1 expression have shorter progression-free survival [278]. Transcriptional induction of ABCA1 by $p 53$ has recently been shown to be involved in p53-mediated suppression of liver tumorigenesis. ABCA1 overexpression blocked SREBP-2 activation and, thereby, the upregulation of the mevalonate pathway [95], possibly by facilitating retrograde sterol transport from the plasma membrane to the endoplasmic reticulum [282]. Collectively, the previous observations suggest that, by impairing LXR-induced expression of ABCA1 and ABCG1 and subsequent cholesterol efflux, SERMs may increase the availability of cholesterol for cell proliferation. However, the effects of SERMs on the LXR pathway are actually a consequence of the blockade of intracellular cholesterol trafficking and cholesterol biosynthesis, thereby restricting cholesterol supply, which is congruent with the SERM-mediated inhibition of cell proliferation and increase of cell death in vitro $[124,174,175]$.

Despite the results above, the LXR pathway has also been involved in cancer progression. $A B C A 1$ expression is elevated in triple negative $B C$ and is associated with the histological grade [283]. High ABCA1 expression and the presence of genetic variants in tumors of colorectal cancer patients are associated with a poor prognosis, and ABCA1 overexpression confers 
increased cell migration and invasive capacities through stabilization of caveolin-1 $[284,285]$. In androgen-independent prostate cancer cells, HDL promotes proliferation and migration by an ABCA1-dependent mechanism involving extracellular signal-regulated kinase (ERK) $1 / 2$ and AKT [286]. With regard to ABCG1, it has been found to be overexpressed in some tumors $[287,288]$ and to be associated with poor prognosis in patients suffering from $B C$ or other carcinomas $[288,289]$. ABCG1 knockdown increased endoplasmic reticulum stress-induced apoptosis in vitro and reduced glioma growth in a mouse model of mesenchymal glioblastoma [288].

Importantly, the LXR pathway may foster tumorigenicity by dampening the immune surveillance. It has been shown that tumors release LXR oxysterol ligands that suppress the expression of CC chemokine receptor-7 on maturing dendritic cells by LXR $\alpha$ activation. This impairs the migration of dendritic cells to draining lymph nodes, thus suppressing the presentation of tumor antigens to T cells [290]. ABCA1 and ABCG1 had a critical role in the tumor-promoting effect of TAMs in a mouse model of metastatic ovarian cancer. These cancer cells secreted hyaluronic acid, which stimulated cholesterol efflux from TAMs and the subsequent destabilization of their membrane lipid rafts. This increased IL-4 signaling, thereby driving an immune-suppressive and tumor-promoting function [291]. Moreover, myeloidspecific ablation of ABCA1 or ABCG1 inhibits melanoma and bladder tumorigenesis in association with reduced accumulation of immune suppressive myeloid-derived suppressor cells in the tumor bed $[292,293]$.

Therefore, different evidence suggests that in certain conditions, which may depend on the tumor microenvironment, the specific genotype or the metabolic state, inhibiting LXR activation and/or $A B C$ transporters expression by SERMs could hinder cancer progression. This could be especially relevant for those processes and microenvironments that dampen the immune response towards tumor cells. In particular, SERMs could blunt the tumor-mediated stimulation of cholesterol efflux from TAMs, thus preventing tumor escape from immune response, an issue that merits further research.

\subsection{Oxysterol metabolism}

Oxysterols are oxidized forms of cholesterol, many of them acting as key effectors in cholesterol homeostasis. Oxysterols have a role in cancer pathophysiology, with disease promoting or suppressing effects through multiple mechanisms, as has been recently and extensively reviewed [43,294-296].

\subsubsection{5,6-Epoxycholesterols and their derivatives}

Tamoxifen and other SERMs cause the accumulation of 5,6 $\alpha$ - and 5,6 $\beta$-epoxycholesterol in cancer cells by stimulating cholesterol peroxidation and simultaneously inhibiting cholesterol5,6 -epoxide hydrolase in an ER-independent manner $[175,297]$. Curiously, this enzymatic activity is carried out by the AEBS, and catalyzes the hydration of 5,6-epoxycholesterols into cholestane-3 $\beta, 5 \alpha, 6 \beta$-triol [298]. Such epoxycholesterols induce cell differentiation and death, although using different mechanisms. Cytotoxicity induced by 5,6ß-epoxycholesterol is linked to the control of the anti-apoptotic protein Bcl-2, but the effect of 5,6 $\alpha$-epoxycholesterol requires its conversion to $5,6 \alpha$-epoxycholesterol-3 $\beta$-sulfate, catalyzed by the sulfotransferase SULT2B1b, and the subsequent modulation of LXR $\beta$ activity by this sulfation product [297]. The accumulation of 5,6-epoxycholesterols and subsequent cell death caused by SERMs and other AEBS ligands were abrogated by the antioxidant vitamin $E$, thus suggesting the involvement of reactive oxygen species in cholesterol epoxidation and cytotoxicity [297]. Moreover, 5,6 $\alpha-$ 
epoxycholesterol has been shown to be an LXR ligand with cell and gene context-dependent effects [299], and in BC MCF-7 cells mediates tamoxifen-induced triacylglycerol biosynthesis through the modulation of LXRß [297].

Inhibiting the formation of cholestane- $3 \beta, 5 \alpha, 6 \beta$-triol by SERMs also prevents its subsequent conversion to another relevant oxysterol, 6 -oxo-cholestan-3 $\beta, 5 \alpha$-diol (OCDO), catalyzed by $11 \beta$-hydroxysteroid-dehydrogenase-type-2 (11ßHSD2) [300], the enzyme that converts cortisol into cortisone. It has been demonstrated that OCDO promotes the proliferation of $B C$ cells by binding to the glucocorticoid receptor, and accelerates the growth of $\mathrm{BC}$ xenografts in mice, irrespective of their ER expression status. In BC patients, the levels of OCDO, its oxysterol precursors and $11 \beta \mathrm{HSD} 2$ were elevated in tumors compared with normal adjacent tissue, and high levels of $11 \beta H S D 2$ mRNA were associated with poor prognosis [300]. In line with this, a recent study in patients with luminal $B C$ found that high plasma levels of cholestane- $3 \beta, 5 \alpha, 6 \beta$ triol were associated with lower disease-free survival [301]. By contrast, however, cholestane$3 \beta, 5 \alpha, 6 \beta$-triol has been shown to suppress proliferation, migration and invasion of prostate cancer cells and to delay xenograft growth in mice [302].

On the other hand, 5,6a-epoxycholesterol condensates with histamine to form dendrogenin A (DDA), which has been characterized as a tumor suppressor [303]. DDA is an AEBS ligand and potent inhibitor of cholesterol-5,6-epoxide hydrolase [304], thus also suppresses OCDO formation [300]. Additionally, DDA binds to LXR $\beta$ to stimulate the expression of Nur77, NOR1 and LC3-II, thus leading to lethal autophagy, a distinct effect not produced by canonical LXR ligands [305]. Interestingly, DDA levels are significantly decreased in breast tumors relative to normal adjacent tissues [304]. Whether tamoxifen, through the accumulation of 5,6 $\alpha$-epoxycholesterol, augments DDA concentration in mammary tumors is unknown. Treatment with DDA triggers BC cell re-differentiation and inhibits tumor growth of several cancers in mouse models $[304,305]$. Therefore, the impact of 5,6-epoxycholesterols and their derivatives on cancer is complex, with some oxysterols displaying tumor suppressing and others tumor promoting actions, suggesting that the balance between these compounds may be critical. Pending new studies, SERMs appear to favor this balance towards tumor suppressing oxysterols, which may contribute to their therapeutic efficacy.

\subsubsection{7-Hydroxycholesterol, an endogenous SERM}

Cholesterol is hydroxylated to 27 -hydroxycholesterol (27HC) by sterol 27-hydroxylase (CYP27A1), a mitochondrial P450 enzyme mainly expressed in liver and macrophages. This oxysterol is catabolized by 25-hydroxycholesterol 7-alpha-hydroxylase (CYP7B1), another P450 enzyme $[306,307]$. $27 \mathrm{HC}$ is the most abundant circulating oxysterol, mainly transported in LDL and $\mathrm{HDL}$, its serum concentration being correlated with that of cholesterol [308,309]. It constitutes a mechanism to deliver excess sterols from peripheral tissues to the liver and is a substrate for bile acid synthesis [306,310]. However, $27 \mathrm{HC}$ has other biologically relevant actions. Aside from activating LXR, 27HC promotes the degradation of HMGCR [311] and inhibits SREBP-2 activation [312], further limiting the availability of intracellular cholesterol. Importantly, 27HC has been characterized as an endogenous SERM that binds to and regulates the transcriptional activity of ER $\alpha$ and $E R \beta[313,314]$. 27HC induces a conformational change in $E R \alpha$ that is distinct from that induced by $17 \beta$-estradiol, 4-hydroxytamoxifen or the antiestrogen ICI 182,780 [314]. In models of cardiovascular disease, $27 \mathrm{HC}$ behaves as an ER antagonist, while in osteoblasts and cellular models of ER-positive BC it behaves as a partial ER agonist [313-316]. Although less potent, 25-hydroxycholesterol also modulates the activity of $E R \alpha$ and promotes breast and ovarian cancer cell proliferation [313,317].

$27 \mathrm{HC}$ has been suggested to be a link between hypercholesterolemia and $B C[307,318]$. 27HC was found to stimulate the proliferation of ER-positive BC cells in vitro and increase breast tumor growth in various murine models [261,270,314]. These effects were ER-dependent, as 
they were inhibited by ICI 182,780 [261,270]. CYP27A1 inhibition or genetic ablation reduced mammary tumor growth [270]. One mechanism mediating the inhibition of proliferation of ERpositive $\mathrm{BC}$ cells by $27 \mathrm{HC}$ is downregulation of $\mathrm{p} 53$ through the $\mathrm{E} 3$ ubiquitin ligase MDM2 [319]. Given that synthetic LXR ligands inhibit cell proliferation and tumor growth (see section 3.5), breast tumor promotion by $27 \mathrm{HC}$ suggests that its ER activating effect predominates over LXR activation. The 27HC-mediated inhibition of cholesterol supply also seems to be ineffective in this setting.

Treatment with $27 \mathrm{HC}$ also increased the expression of markers of epithelial to mesenchymal transition (EMT) and the number of metastatic foci in mice lungs [270,320]. However, this effect was independent of ER and involved LXR activation. In fact, the pro-metastatic role of $27 \mathrm{HC}$ is quite complex [318,321]. For example, $27 \mathrm{HC}$ increased EMT hallmarks and migratory and invasive capacities of ER-positive and ER-negative BC cells via activation of the signal transducer and activator of transcription (STAT) 3 [322]. Moreover, 27HC exerts cancer-cell extrinsic effects that contribute to metastasis, such as stimulating the function of polymorphonuclear-neutrophils and $\gamma \delta$-T cells [320]. $27 \mathrm{HC}$ might also have a role in developing resistance to estrogen deprivation. Under long-term estrogen deprivation, ER-positive BC cells increased the expression of cholesterol biosynthetic and CYP27A1 genes and the binding of $E R \alpha$ to regulatory elements, suggesting that endogenously generated $27 \mathrm{HC}$ can substitute for estrogen [154].

There is clinical evidence for a pathological role of $27 \mathrm{HC}$ in $\mathrm{BC}$. Concentrations of this oxysterol within ER-positive breast tumors are higher than in adjacent normal tissue, and are higher in adjacent normal tissue than in breast tissue from healthy women [261]. Increased expression of CYP7B1 mRNA in tumors is associated with increased patient survival [261,270,307].

Expression of CYP27A1 protein was found to be elevated in tumor cells and macrophages of higher-grade tumors [270]. Actually, macrophages highly express CYP27A1 [270], and it is documented that TAMs are a poor prognostic factor [256]. However, later analysis showed that elevated tumoral expression of CYP27A1 mRNA is a beneficial prognostic indicator, an association only apparent in ER $\alpha$-positive cases and in women aged $\leq 50$ years [307]. A number of studies have reported the involvement of $27 \mathrm{HC}$ in other types of cancer, such as thyroid carcinoma [323] and glioblastoma [324]. However, the role of $27 \mathrm{HC}$ in certain cancers, including prostate cancer, is unclear, due to existing conflicting results $[43,318,321]$. Whatever the reason, the possibility exists that the role of $27 \mathrm{HC}$ in a particular cancer depends on the predominant mechanism involved, i.e. ERs, LXRs or others.

The effect of synthetic SERMs on $27 \mathrm{HC}$ signaling is unknown. Presumably, by inhibiting cholesterol biosynthesis and trafficking, synthetic SERMs may impair the generation of 27HC, and they may also reduce the availability of LDL-derived 27HC. Furthermore, SERMs might compete with $27 \mathrm{HC}$ for binding to or alter the interaction of $27 \mathrm{HC}$ with ERs, thus lowering $E R$ activity. Research on this subject is warranted.

\section{Concluding remarks}

Cancer progression is contingent on cellular cholesterol metabolism reprogramming to meet the requirements of cancer cells. Not only do different oncogenic signals target cholesterol metabolism to ensure cholesterol availability for cell proliferation, but also cholesterol and certain oxysterols modulate different pathways critical for tumor progression, including those involved in the immune response. Many of these pathways have been proposed as therapeutic targets, and it is conceivable that restricting cholesterol supply can also improve other therapeutic interventions. SERMs display a complex pharmacology, with multiple effects exerted through either ER-dependent or independent mechanisms. In large part through the 
latter mechanisms, SERMs broadly affect cellular cholesterol metabolism and handling, including cholesterol supply, storage, export and oxidation (Fig. 2), which may expand the anticancer properties of these drugs. It is noteworthy that several effects of SERMs on cholesterol homeostasis rely on the interference with endolysosomal cholesterol trafficking and, thus, restriction of exogenous cholesterol supply. Another remarkable consequence of this cholesterol traffic jam may be the abrogation of oncogenic signaling through mTORC1. Additionally, suppressing de novo biosynthesis by SERMs further limits cholesterol availability and produces the accumulation of intermediate sterols with potential regulatory actions. The simultaneous inhibition of endogenous and exogenous cholesterol supply blunts the SREBPmediated regulatory response. The modulation of the formation of different oxysterols may also play a significant role in the therapeutic efficacy of SERMs. In particular, decreasing cholesterol availability may impair the generation of 27HC, an endogenous SERM with cancer promoting activity. However, synthetic SERMs are not exempt from potentially harmful effects. The activation of the SREBP pathway to restore cholesterol supply and the inability to activate the LXR pathway and cholesterol efflux in SERM-treated cells might eventually counterbalance the shortage of intracellular cholesterol and constitute a mechanism of treatment resistance. The SERM-induced increase in SR-BI expression may also compensate for cholesterol deprivation and, moreover, stimulate oncogenic signaling. Nevertheless, shutting off the LXR pathway is a potential mechanism to abrogate other processes crucial for cancer progression, such as those driving metastatic dissemination or tumor immune evasion. A still unaddressed but pertinent question is how SERMs affect the expression of microRNAs relevant to cholesterol homeostasis. MicroRNAs are critical post-transcriptional regulators of cholesterol metabolism [325] and, on the other hand, microRNA expression profiling has been shown to be associated with tumour development, progression and response to therapy $[30,326]$. Delineating the contribution of these processes to the therapeutic effect of SERMs is essential. This knowledge could be eventually exploited in the design of new therapeutic strategies.

\section{References}

[1] Riggs BL, Hartmann LC. Selective estrogen-receptor modulators -- mechanisms of action and application to clinical practice. N Engl J Med 2003;348:618-29.

[2] Ali S, Buluwela L, Coombes RC. Antiestrogens and their therapeutic applications in breast cancer and other diseases. Annu Rev Med 2011;62:217-32.

[3] Martinkovich S, Shah D, Planey SL, Arnott JA. Selective estrogen receptor modulators: tissue specificity and clinical utility. Clin Interv Aging 2014;9:1437-52.

[4] Pickar JH, MacNeil T, Ohleth K. SERMs: progress and future perspectives. Maturitas 2010;67:129-38.

[5] Maximov PY, Lee TM, Jordan VC. The discovery and development of selective estrogen receptor modulators (SERMs) for clinical practice. Curr Clin Pharmacol 2013;8:135-55.

[6] Patel HK, Bihani T. Selective estrogen receptor modulators (SERMs) and selective estrogen receptor degraders (SERDs) in cancer treatment. Pharmacol Ther 2018;186:1-24.

[7] Haldosen LA, Zhao C, Dahlman-Wright K. Estrogen receptor beta in breast cancer. Mol Cell Endocrinol 2014;382:665-72.

[8] Huang B, Omoto Y, Iwase H, Yamashita H, Toyama T, Coombes RC et al. Differential expression of estrogen receptor alpha, beta1, and beta2 in lobular and ductal breast cancer. Proc Natl Acad Sci U S A 2014;111:1933-8. 
[9] Goetz MP, Kamal A, Ames MM. Tamoxifen pharmacogenomics: the role of CYP2D6 as a predictor of drug response. Clin Pharmacol Ther 2008;83:160-6.

[10] Stearns V, Rae JM. Pharmacogenetics and breast cancer endocrine therapy: CYP2D6 as a predictive factor for tamoxifen metabolism and drug response? Expert Rev Mol Med

2008;10:e34.

[11] Osborne CK, Schiff R. Mechanisms of endocrine resistance in breast cancer. Annu Rev Med 2011;62:233-47.

[12] Gelmann EP. Tamoxifen induction of apoptosis in estrogen receptor-negative cancers: new tricks for an old dog? J Natl Cancer Inst 1996;88:224-6.

[13] de Medina P, Favre G, Poirot M. Multiple targeting by the antitumor drug tamoxifen: a structure-activity study. Curr Med Chem Anticancer Agents 2004;4:491-508.

[14] O'Brian CA, Liskamp RM, Solomon DH, Weinstein IB. Inhibition of protein kinase C by tamoxifen. Cancer Res 1985;45:2462-5.

[15] Gundimeda U, Chen ZH, Gopalakrishna R. Tamoxifen modulates protein kinase C via oxidative stress in estrogen receptor-negative breast cancer cells. J Biol Chem 1996;271:1350414.

[16] Matsuoka H, Tsubaki M, Yamazoe Y, Ogaki M, Satou T, Itoh T et al. Tamoxifen inhibits tumor cell invasion and metastasis in mouse melanoma through suppression of PKC/MEK/ERK and PKC/PI3K/Akt pathways. Exp Cell Res 2009;315:2022-32.

[17] Yang L, Yuan X, Wang J, Gu C, Zhang H, Yu J et al. Radiosensitization of human glioma cells by tamoxifen is associated with the inhibition of PKC-iota activity in vitro. Oncol Lett 2015;10:473-8.

[18] Manna S, Holz MK. Tamoxifen action in ER-negative breast cancer. Sign Transduct Insights 2016;5:1-7.

[19] Bruning PF, Bonfrer JM, Hart AA, de Jong-Bakker M, Linders D, van Loon J et al. Tamoxifen, serum lipoproteins and cardiovascular risk. Br J Cancer 1988;58:497-9.

[20] Hong N, Yoon HG, Seo DH, Park S, Kim SI, Sohn JH et al. Different patterns in the risk of newly developed fatty liver and lipid changes with tamoxifen versus aromatase inhibitors in postmenopausal women with early breast cancer: A propensity score-matched cohort study. Eur J Cancer 2017;82:103-14.

[21] Kusama M, Miyauchi K, Aoyama H, Sano M, Kimura M, Mitsuyama S et al. Effects of toremifene (TOR) and tamoxifen (TAM) on serum lipids in postmenopausal patients with breast cancer. Breast Cancer Res Treat 2004;88:1-8.

[22] Tominaga T, Kimijima I, Kimura M, Takatsuka Y, Takashima S, Nomura Y et al. Effects of toremifene and tamoxifen on lipid profiles in post-menopausal patients with early breast cancer: interim results from a Japanese phase III trial. Jpn J Clin Oncol 2010;40:627-33.

[23] Banerjee S, Smith IE, Folkerd L, Iqbal J, Barker P, Dowsett M et al. Comparative effects of anastrozole, tamoxifen alone and in combination on plasma lipids and bone-derived resorption during neoadjuvant therapy in the impact trial. Ann Oncol 2005;16:1632-8.

[24] Clarke SC, Schofield PM, Grace AA, Metcalfe JC, Kirschenlohr HL. Tamoxifen effects on endothelial function and cardiovascular risk factors in men with advanced atherosclerosis.

Circulation 2001;103:1497-502.

[25] Hozumi Y, Kawano M, Saito T, Miyata M. Effect of tamoxifen on serum lipid metabolism. J Clin Endocrinol Metab 1998;83:1633-5.

[26] Thangaraju M, Kumar K, Gandhirajan R, Sachdanandam P. Effect of tamoxifen on plasma lipids and lipoproteins in postmenopausal women with breast cancer. Cancer 1994;73:659-63.

[27] Hozumi Y, Kawano M, Miyata M. Severe hypertriglyceridemia caused by tamoxifentreatment after breast cancer surgery. Endocr J 1997;44:745-9.

[28] Tabas I. Consequences of cellular cholesterol accumulation: basic concepts and physiological implications. J Clin Invest 2002;110:905-11. 
[29] Luo J, Yang H, Song BL. Mechanisms and regulation of cholesterol homeostasis. Nat Rev Mol Cell Biol 2020;21:225-45.

[30] Lasuncion MA, Martin-Sanchez C, Canfran-Duque A, Busto R. Post-lanosterol biosynthesis of cholesterol and cancer. Curr Opin Pharmacol 2012;12:717-23.

[31] Vitols S, Norgren S, Juliusson G, Tatidis L, Luthman H. Multilevel regulation of low-density lipoprotein receptor and 3-hydroxy-3-methylglutaryl coenzyme A reductase gene expression in normal and leukemic cells. Blood 1994;84:2689-98.

[32] Chen HW, Heiniger HJ, Kandutsch AA. Relationship between sterol synthesis and DNA synthesis in phytohemagglutinin-stimulated mouse lymphocytes. Proceedings of the National Academy of Sciences 1975;72:1950-4.

[33] Bensinger SJ, Bradley MN, Joseph SB, Zelcer N, Janssen EM, Hausner MA et al. LXR signaling couples sterol metabolism to proliferation in the acquired immune response. Cell 2008;134:97-111.

[34] Zabielska J, Sledzinski T, Stelmanska E. Acyl-coenzyme A: cholesterol acyltransferase inhibition in cancer treatment. Anticancer Res 2019;39:3385-94.

[35] Brown MS, Goldstein JL. Cholesterol feedback: from Schoenheimer's bottle to Scap's MELADL. J Lipid Res 2009;50 Suppl:S15-27.

[36] Shimano H, Sato R. SREBP-regulated lipid metabolism: convergent physiology - divergent pathophysiology. Nat Rev Endocrinol 2017;13:710-30.

[37] Wang B, Tontonoz P. Liver $X$ receptors in lipid signalling and membrane homeostasis. Nat Rev Endocrinol 2018;14:452-63.

[38] Swyer GIM. The cholesterol content of normal and enlarged prostates. Cancer Res 1942;2:372-5.

[39] Dessi S, Batetta B, Pulisci D, Spano O, Anchisi C, Tessitore L et al. Cholesterol content in tumor tissues is inversely associated with high-density lipoprotein cholesterol in serum in patients with gastrointestinal cancer. Cancer 1994;73:253-8.

[40] Kolanjiappan K, Ramachandran CR, Manoharan S. Biochemical changes in tumor tissues of oral cancer patients. Clin Biochem 2003;36:61-5.

[41] Stopsack KH, Gerke TA, Sinnott JA, Penney KL, Tyekucheva S, Sesso HD et al. Cholesterol metabolism and prostate cancer lethality. Cancer Res 2016;76:4785-90.

[42] Cheng C, Geng F, Cheng X, Guo D. Lipid metabolism reprogramming and its potential targets in cancer. Cancer Commun (Lond) 2018;38:27.

[43] Riscal R, Skuli N, Simon MC. Even cancer cells watch their cholesterol! Mol Cell 2019;76:220-31.

[44] Rose G, Blackburn H, Keys A, Taylor HL, Kannel WB, Paul O et al. Colon cancer and bloodcholesterol. Lancet 1974;1:181-3.

[45] Williams RR, Sorlie PD, Feinleib M, McNamara PM, Kannel WB, Dawber TR. Cancer incidence by levels of cholesterol. JAMA 1981;245:247-52.

[46] Stemmermann GN, Nomura AM, Heilbrun LK, Pollack ES, Kagan A. Serum cholesterol and colon cancer incidence in Hawaiian Japanese men. J Natl Cancer Inst 1981;67:1179-82.

[47] McMichael AJ, Jensen OM, Parkin DM, Zaridze DG. Dietary and endogenous cholesterol and human cancer. Epidemiol Rev 1984;6:192-216.

[48] Isles CG, Hole DJ, Gillis CR, Hawthorne VM, Lever AF. Plasma cholesterol, coronary heart disease, and cancer in the Renfrew and Paisley survey. BMJ 1989;298:920-4.

[49] Kritchevsky SB, Kritchevsky D. Serum cholesterol and cancer risk: an epidemiologic perspective. Annu Rev Nutr 1992;12:391-416.

[50] Circulating cholesterol level and risk of death from cancer in men aged 40 to 69 years. Experience of an international collaborative group. JAMA 1982;248:2853-9.

[51] Winawer SJ, Flehinger BJ, Buchalter J, Herbert E, Shike M. Declining serum cholesterol levels prior to diagnosis of colon cancer. A time-trend, case-control study. JAMA 1990;263:2083-5. 
[52] Iribarren C, Reed DM, Chen R, Yano K, Dwyer JH. Low serum cholesterol and mortality. Which is the cause and which is the effect? Circulation 1995;92:2396-403.

[53] Inbar M, Shinitzky M. Cholesterol as a bioregulator in the development and inhibition of leukemia. Proc Natl Acad Sci U S A 1974;71:4229-31.

[54] Schatzkin A, Hoover RN, Taylor PR, Ziegler RG, Carter CL, Albanes D et al. Site-specific analysis of total serum cholesterol and incident cancer in the National Health and Nutrition Examination Survey I Epidemiologic Follow-up Study. Cancer Res 1988;48:452-8.

[55] Muller CP, Wagner AU, Maucher C, Steinke B. Hypocholesterolemia, an unfavorable feature of prognostic value in chronic myeloid leukemia. Eur J Haematol 1989;43:235-9.

[56] Kitahara CM, Berrington de Gonzalez A, Freedman ND, Huxley R, Mok Y, Jee SH et al. Total cholesterol and cancer risk in a large prospective study in Korea. J Clin Oncol 2011;29:1592-8. [57] Shafique K, McLoone P, Qureshi K, Leung H, Hart C, Morrison DS. Cholesterol and the risk of grade-specific prostate cancer incidence: evidence from two large prospective cohort studies with up to 37 years' follow up. BMC Cancer 2012;12:25.

[58] Touvier M, Fassier P, His M, Norat T, Chan DS, Blacher J et al. Cholesterol and breast cancer risk: a systematic review and meta-analysis of prospective studies. $\mathrm{Br} \mathrm{J}$ Nutr 2015;114:347-57.

[59] Vogel VG, McPherson RS. Dietary epidemiology of colon cancer. Hematol Oncol Clin North Am 1989;3:35-63.

[60] Hu J, La Vecchia C, de Groh M, Negri E, Morrison H, Mery L et al. Dietary cholesterol intake and cancer. Ann Oncol 2012;23:491-500.

[61] Pelton K, Freeman MR, Solomon KR. Cholesterol and prostate cancer. Curr Opin Pharmacol 2012;12:751-9.

[62] Radisauskas R, Kuzmickiene I, Milinaviciene E, Everatt R. Hypertension, serum lipids and cancer risk: A review of epidemiological evidence. Medicina (Kaunas) 2016;52:89-98.

[63] Bonovas S, Filioussi K, Tsavaris N, Sitaras NM. Statins and cancer risk: a literature-based meta-analysis and meta-regression analysis of 35 randomized controlled trials. J Clin Oncol 2006;24:4808-17.

[64] Desai P, Lehman A, Chlebowski RT, Kwan ML, Arun M, Manson JE et al. Statins and breast cancer stage and mortality in the Women's Health Initiative. Cancer Causes Control 2015;26:529-39.

[65] Borgquist S, Tamimi RM, Chen WY, Garber JE, Eliassen AH, Ahern TP. Statin use and breast cancer risk in the Nurses' Health Study. Cancer Epidemiol Biomarkers Prev 2016;25:201-6.

[66] Babcook MA, Joshi A, Montellano JA, Shankar E, Gupta S. Statin use in prostate cancer: An update. Nutr Metab Insights 2016;9:43-50.

[67] Setoguchi S, Glynn RJ, Avorn J, Mogun H, Schneeweiss S. Statins and the risk of lung, breast, and colorectal cancer in the elderly. Circulation 2007;115:27-33.

[68] Wang J, Li C, Tao H, Cheng Y, Han L, Li X et al. Statin use and risk of lung cancer: a metaanalysis of observational studies and randomized controlled trials. PLoS One 2013;8:e77950.

[69] Singh H, Mahmud SM, Turner D, Xue L, Demers AA, Bernstein CN. Long-term use of statins and risk of colorectal cancer: a population-based study. Am J Gastroenterol 2009;104:3015-23. [70] Nielsen SF, Nordestgaard BG, Bojesen SE. Statin use and reduced cancer-related mortality. N Engl J Med 2012;367:1792-802.

[71] Zhong S, Zhang X, Chen L, Ma T, Tang J, Zhao J. Statin use and mortality in cancer patients: Systematic review and meta-analysis of observational studies. Cancer Treat Rev 2015;41:55467.

[72] Ahern TP, Pedersen L, Tarp M, Cronin-Fenton DP, Garne JP, Silliman RA et al. Statin prescriptions and breast cancer recurrence risk: a Danish nationwide prospective cohort study. J Natl Cancer Inst 2011;103:1461-8. 
[73] Manthravadi S, Shrestha A, Madhusudhana S. Impact of statin use on cancer recurrence and mortality in breast cancer: A systematic review and meta-analysis. Int J Cancer 2016;139:1281-8.

[74] Tan P, Wei S, Yang L, Tang Z, Cao D, Liu L et al. The effect of statins on prostate cancer recurrence and mortality after definitive therapy: a systematic review and meta-analysis. Sci Rep 2016;6:29106.

[75] Lin JJ, Ezer N, Sigel K, Mhango G, Wisnivesky JP. The effect of statins on survival in patients with stage IV lung cancer. Lung Cancer 2016;99:137-42.

[76] Lash TL, Riis AH, Ostenfeld EB, Erichsen R, Vyberg M, Ahern TP et al. Associations of statin use with colorectal cancer recurrence and mortality in a Danish cohort. Am J Epidemiol 2017;186:679-87.

[77] Beckwitt CH, Brufsky A, Oltvai ZN, Wells A. Statin drugs to reduce breast cancer recurrence and mortality. Breast Cancer Res 2018;20:144.

[78] Kerr J, Anderson C, Lippman SM. Physical activity, sedentary behaviour, diet, and cancer: an update and emerging new evidence. Lancet Oncol 2017;18:e457-e71.

[79] Chen H, Qin S, Wang M, Zhang T, Zhang S. Association between cholesterol intake and pancreatic cancer risk: evidence from a meta-analysis. Sci Rep 2015;5:8243.

[80] Li C, Yang L, Zhang D, Jiang W. Systematic review and meta-analysis suggest that dietary cholesterol intake increases risk of breast cancer. Nutr Res 2016;36:627-35.

[81] Staley C, Weingarden AR, Khoruts A, Sadowsky MJ. Interaction of gut microbiota with bile acid metabolism and its influence on disease states. Appl Microbiol Biotechnol 2017;101:47-

64.

[82] Rezasoltani S, Sadeghi A, Radinnia E, Naseh A, Gholamrezaei Z, Azizmohammad Looha M et al. The association between gut microbiota, cholesterol gallstones, and colorectal cancer. Gastroenterol Hepatol Bed Bench 2019;12:S8-S13.

[83] Huang B, Song BL, Xu C. Cholesterol metabolism in cancer: mechanisms and therapeutic opportunities. Nat Metab 2020;2:132-41.

[84] Chen HW, Kandutsch AA, Waymouth C. Inhibition of cell growth by oxygenated derivatives of cholesterol. Nature 1974;251:419-21.

[85] Brown MS, Goldstein JL. Suppression of 3-hydroxy-3-methylglutaryl coenzyme A reductase activity and inhibition of growth of human fibroblasts by 7-ketocholesterol. J Biol Chem 1974;249:7306-14.

[86] Suarez Y, Fernandez C, Ledo B, Martin M, Gomez-Coronado D, Lasuncion MA. Sterol stringency of proliferation and cell cycle progression in human cells. Biochim Biophys Acta 2005;1734:203-13.

[87] Rodríguez-Acebes S, Cueva P, Fernández-Hernando C, Ferruelo AJ, Lasuncion MA, Rawson $\mathrm{RB}$ et al. Desmosterol can replace cholesterol in sustaining cell proliferation and regulating the SREBP pathway in a sterol- $\Delta^{24}$-reductase-deficient cell line. Biochemical J 2009;420:305-18. [88] Rodriguez-Acebes S, Cueva P, Ferruelo AJ, Fernandez-Hernando C, Lasuncion MA, Martinez-Botas J et al. Dose-dependent dual effects of cholesterol and desmosterol on $\mathrm{J774}$ macrophage proliferation. Biochem Biophys Res Commun 2008;377:484-8.

[89] Rujanavech C, Silbert DF. Effect of sterol structure on the partition of sterol between phospholipid vesicles of different composition. J Biol Chem 1986;261:7215-9.

[90] Suárez Y, Fernández C, Ledo B, Ferruelo AJ, Martín M, Vega MA et al. Differential effects of ergosterol and cholesterol on Cdk1 activation and SRE-driven transcription. European Journal of Biochemistry 2002;269:1761-71.

[91] Xu F, Rychnovsky SD, Belani JD, Hobbs HH, Cohen JC, Rawson RB. Dual roles for cholesterol in mammalian cells. 2005;102:14551-6.

[92] Freed-Pastor WA, Mizuno H, Zhao X, Langerod A, Moon SH, Rodriguez-Barrueco R et al. Mutant p53 disrupts mammary tissue architecture via the mevalonate pathway. Cell 2012;148:244-58. 
[93] Parrales A, Ranjan A, Swathi, Padhye S, Scott, Roy A et al. DNAJA1 controls the fate of misfolded mutant p53 through the mevalonate pathway. Nature Cell Biology 2016;18:1233-43. [94] Xu D, Tong X, Sun L, Li H, Jones RD, Liao J et al. Inhibition of mutant Kras and p53-driven pancreatic carcinogenesis by atorvastatin: Mainly via targeting of the farnesylated DNAJA1 in chaperoning mutant p53. Mol Carcinog 2019;58:2052-64.

[95] Moon SH, Huang CH, Houlihan SL, Regunath K, Freed-Pastor WA, Morris JPt et al. p53 Represses the Mevalonate Pathway to Mediate Tumor Suppression. Cell 2019;176:564-80 e19. [96] Cuthbert JA, Lipsky PE. Lipoproteins may provide fatty acids necessary for human lymphocyte proliferation by both low density lipoprotein receptor-dependent and independent mechanisms. J Biol Chem 1989;264:13468-74.

[97] Martinez-Botas J, Suarez Y, Reshef A, Carrero P, Ortega H, Gomez-Coronado D et al. Impact of different low-density lipoprotein (LDL) receptor mutations on the ability of LDL to support lymphocyte proliferation. Metabolism 1999;48:834-9.

[98] Keyomarsi K, Sandoval L, Band V, Pardee AB. Synchronization of tumor and normal cells from $\mathrm{G} 1$ to multiple cell cycles by lovastatin. Cancer Res 1991;51:3602-9.

[99] Poon RY, Toyoshima H, Hunter T. Redistribution of the CDK inhibitor p27 between different cyclin.CDK complexes in the mouse fibroblast cell cycle and in cells arrested with lovastatin or ultraviolet irradiation. Mol Biol Cell 1995;6:1197-213.

[100] Rao S, Lowe M, Herliczek TW, Keyomarsi K. Lovastatin mediated G1 arrest in normal and tumor breast cells is through inhibition of CDK2 activity and redistribution of p21 and p27, independent of p53. Oncogene 1998;17:2393-402.

[101] Park WH, Lee YY, Kim ES, Seol JG, Jung CW, Lee CC et al. Lovastatin-induced inhibition of HL-60 cell proliferation via cell cycle arrest and apoptosis. Anticancer Res 1999;19:3133-40.

[102] Singh P, Saxena R, Srinivas G, Pande G, Chattopadhyay A. Cholesterol biosynthesis and homeostasis in regulation of the cell cycle. PLoS One 2013;8:e58833.

[103] Martinez-Botas J, Suarez Y, Ferruelo AJ, Gomez-Coronado D, Lasuncion MA. Cholesterol starvation decreases p34(cdc2) kinase activity and arrests the cell cycle at G2. FASEB J 1999;13:1359-70.

[104] Fernandez C, Martin M, Gomez-Coronado D, Lasuncion MA. Effects of distal cholesterol biosynthesis inhibitors on cell proliferation and cell cycle progression. J Lipid Res 2005;46:9209.

[105] Fernandez C, Lobo MV, Gomez-Coronado D, Lasuncion MA. Cholesterol is essential for mitosis progression and its deficiency induces polyploid cell formation. Exp Cell Res 2004;300:109-20.

[106] Ng MM, Chang F, Burgess DR. Movement of membrane domains and requirement of membrane signaling molecules for cytokinesis. Dev Cell 2005;9:781-90.

[107] Bengoechea-Alonso MT, Punga T, Ericsson J. Hyperphosphorylation regulates the activity of SREBP1 during mitosis. Proc Natl Acad Sci U S A 2005;102:11681-6.

[108] Bengoechea-Alonso MT, Ericsson J. Cdk1/cyclin B-mediated phosphorylation stabilizes SREBP1 during mitosis. Cell Cycle 2006;5:1708-18.

[109] Theodoropoulos PC, Wang W, Budhipramono A, Thompson BM, Madhusudhan N, Mitsche MA et al. A medicinal chemistry-driven approach identified the sterol isomerase EBP as the molecular target of TASIN colorectal cancer toxins. J Am Chem Soc 2020;142:6128-38. [110] Kelley RI, Herman GE. Inborn errors of sterol biosynthesis. Annu Rev Genomics Hum Genet 2001;2:299-341.

[111] Porter FD, Herman GE. Malformation syndromes caused by disorders of cholesterol synthesis. J Lipid Res 2011;52:6-34.

[112] Herman GE, Kratz L. Disorders of sterol synthesis: beyond Smith-Lemli-Opitz syndrome. Am J Med Genet C Semin Med Genet 2012;160C:301-21.

[113] Langan TJ, Volpe JJ. Cell cycle-specific requirement for mevalonate, but not for cholesterol, for DNA synthesis in glial primary cultures. J Neurochem 1987;49:513-21. 
[114] Siperstein MD. Role of cholesterogenesis and isoprenoid synthesis in DNA replication and cell growth. J Lipid Res 1984;25:1462-8.

[115] Quesney-Huneeus V, Galick HA, Siperstein MD, Erickson SK, Spencer TA, Nelson JA. The dual role of mevalonate in the cell cycle. J Biol Chem 1983;258:378-85.

[116] Perez-Sala D, Mollinedo F. Inhibition of isoprenoid biosynthesis induces apoptosis in human promyelocytic HL-60 cells. Biochem Biophys Res Commun 1994;199:1209-15.

[117] Dimitroulakos J, Nohynek D, Backway KL, Hedley DW, Yeger H, Freedman MH et al. Increased sensitivity of acute myeloid leukemias to lovastatin-induced apoptosis: A potential therapeutic approach. Blood 1999;93:1308-18.

[118] Sepp-Lorenzino L, Rao S, Coleman PS. Cell-cycle-dependent, differential prenylation of proteins. Eur J Biochem 1991;200:579-90.

[119] Jakobisiak M, Bruno S, Skierski JS, Darzynkiewicz Z. Cell cycle-specific effects of lovastatin. Proc Natl Acad Sci U S A 1991;88:3628-32.

[120] Vogt A, Qian Y, McGuire TF, Hamilton AD, Sebti SM. Protein geranylgeranylation, not farnesylation, is required for the $\mathrm{G} 1$ to $\mathrm{S}$ phase transition in mouse fibroblasts. Oncogene 1996;13:1991-9.

[121] Martin Sanchez C, Perez Martin JM, Jin JS, Davalos A, Zhang W, de la Pena G et al. Disruption of the mevalonate pathway induces dNTP depletion and DNA damage. Biochim Biophys Acta 2015;1851:1240-53.

[122] Gaillard H, Garcia-Muse T, Aguilera A. Replication stress and cancer. Nat Rev Cancer 2015;15:276-89.

[123] Lecona E, Fernandez-Capetillo O. Targeting ATR in cancer. Nat Rev Cancer 2018;18:58695.

[124] Payre B, de Medina P, Boubekeur N, Mhamdi L, Bertrand-Michel J, Terce F et al.

Microsomal antiestrogen-binding site ligands induce growth control and differentiation of human breast cancer cells through the modulation of cholesterol metabolism. Mol Cancer Ther 2008;7:3707-18.

[125] Cho SJ, Kim JS, Kim JM, Lee JY, Jung HC, Song IS. Simvastatin induces apoptosis in human colon cancer cells and in tumor xenografts, and attenuates colitis-associated colon cancer in mice. Int J Cancer 2008;123:951-7.

[126] Liang Z, Li W, Liu J, Li J, He F, Jiang Y et al. Simvastatin suppresses the DNA replication licensing factor MCM7 and inhibits the growth of tamoxifen-resistant breast cancer cells. Sci Rep 2017;7:41776.

[127] Wang ST, Ho HJ, Lin JT, Shieh JJ, Wu CY. Simvastatin-induced cell cycle arrest through inhibition of STAT3/SKP2 axis and activation of AMPK to promote p27 and p21 accumulation in hepatocellular carcinoma cells. Cell Death Dis 2017;8:e2626.

[128] Hagiwara N, Watanabe M, lizuka-Ohashi M, Yokota I, Toriyama S, Sukeno M et al. Mevalonate pathway blockage enhances the efficacy of mTOR inhibitors with the activation of retinoblastoma protein in renal cell carcinoma. Cancer Lett 2018;431:182-9.

[129] Liang Y, Mafuvadze B, Aebi JD, Hyder SM. Cholesterol biosynthesis inhibitor RO 48-8071 suppresses growth of hormone-dependent and castration-resistant prostate cancer cells. Onco Targets Ther 2016;9:3223-32.

[130] Lopez-Barcons L, Maurer BJ, Kang MH, Reynolds CP. P450 inhibitor ketoconazole increased the intratumor drug levels and antitumor activity of fenretinide in human neuroblastoma xenograft models. Int J Cancer 2017;141:405-13.

[131] Agnihotri S, Mansouri S, Burrell K, Li M, Mamatjan Y, Liu J et al. Ketoconazole and posaconazole selectively target HK2-expressing glioblastoma cells. Clin Cancer Res 2019;25:844-55.

[132] Sukhanova A, Gorin A, Serebriiskii IG, Gabitova L, Zheng H, Restifo D et al. Targeting C4demethylating genes in the cholesterol pathway sensitizes cancer cells to EGF receptor inhibitors via increased EGF receptor degradation. Cancer Discov 2013;3:96-111. 
[133] Bi X, Han X, Zhang F, He M, Zhang Y, Zhi XY et al. Triparanol suppresses human tumor growth in vitro and in vivo. Biochem Biophys Res Commun 2012;425:613-8.

[134] Zhang L, Theodoropoulos PC, Eskiocak U, Wang W, Moon YA, Posner B et al. Selective targeting of mutant adenomatous polyposis coli (APC) in colorectal cancer. Sci Transl Med 2016;8:361ra140.

[135] Dimitroulakos J, Thai S, Wasfy GH, Hedley DW, Minden MD, Penn LZ. Lovastatin induces a pronounced differentiation response in acute myeloid leukemias. Leuk Lymphoma 2000;40:167-78.

[136] Cooper RA, Ip SH, Cassileth PA, Kuo AL. Inhibition of sterol and phospholipid synthesis in $\mathrm{HL}-60$ promyelocytic leukemia cells by inducers of myeloid differentiation. Cancer Res 1981;41:1847-52.

[137] Fogelman AM, Seager J, Edwards PA, Hokom M, Popjak G. Cholesterol biosynthesis in human lymphocytes, monocytes, and granulocytes. Biochem Biophys Res Commun 1977;76:167-73.

[138] Shechter I, Fogelman AM, Popjak G. A deficiency of mixed function oxidase activities in the cholesterol biosynthetic pathway of human granulocytes. J Lipid Res 1980;21:277-83.

[139] Sanchez-Martin CC, Davalos A, Martin-Sanchez C, de la Pena G, Fernandez-Hernando C, Lasuncion MA. Cholesterol starvation induces differentiation of human leukemia HL-60 cells. Cancer Res 2007;67:3379-86.

[140] Mejia-Pous C, Damiola F, Gandrillon O. Cholesterol synthesis-related enzyme oxidosqualene cyclase is required to maintain self-renewal in primary erythroid progenitors.

Cell Prolif 2011;44:441-52.

[141] Rozman D. Lanosterol 14alpha-demethylase (CYP51)--a cholesterol biosynthetic enzyme involved in production of meiosis activating sterols in oocytes and testis--a minireview.

Pflugers Arch 2000;439:R56-7.

[142] Byskov AG, Andersen CY, Leonardsen L. Role of meiosis activating sterols, MAS, in induced oocyte maturation. Mol Cell Endocrinol 2002;187:189-96.

[143] Rozman D, Seliskar M, Cotman M, Fink M. Pre-cholesterol precursors in gametogenesis. Mol Cell Endocrinol 2005;234:47-56.

[144] Keber R, Rozman D, Horvat S. Sterols in spermatogenesis and sperm maturation. J Lipid Res 2013;54:20-33.

[145] Shi JF, Li YK, Ren K, Xie YJ, Yin WD, Mo ZC. Characterization of cholesterol metabolism in Sertoli cells and spermatogenesis (Review). Mol Med Rep 2018;17:705-13.

[146] Wang F, Yang J, Wang H, Xia G. Gonadotropin-regulated expressions of lanosterol 14alpha-demethylase, sterol Delta14-reductase and C-4 sterol methyl oxidase contribute to the accumulation of meiosis-activating sterol in rabbit gonads. Prostaglandins Other Lipid Mediat 2010;92:25-32.

[147] Byskov AG, Andersen CY, Leonardsen L, Baltsen M. Meiosis activating sterols (MAS) and fertility in mammals and man. J Exp Zool 1999;285:237-42.

[148] Marco-Jimenez F, Llobat L, Vicente JS. Effects of lanosterol on in vitro maturation of porcine oocytes. Anim Reprod Sci 2010;117:288-94.

[149] Hubler Z, Allimuthu D, Bederman I, Elitt MS, Madhavan M, Allan KC et al. Accumulation of 8,9-unsaturated sterols drives oligodendrocyte formation and remyelination. Nature 2018;560:372-6.

[150] Allimuthu D, Hubler Z, Najm FJ, Tang H, Bederman I, Seibel W et al. Diverse chemical scaffolds enhance oligodendrocyte formation by inhibiting CYP51, TM7SF2, or EBP. Cell Chem Biol 2019;26:593-9 e4.

[151] Silvente-Poirot S, Poirot M. Cholesterol epoxide hydrolase and cancer. Curr Opin Pharmacol 2012;12:696-703. 
[152] Leignadier J, Dalenc F, Poirot M, Silvente-Poirot S. Improving the efficacy of hormone therapy in breast cancer: The role of cholesterol metabolism in SERM-mediated autophagy, cell differentiation and death. Biochem Pharmacol 2017;144:18-28.

[153] Mullen PJ, Yu R, Longo J, Archer MC, Penn LZ. The interplay between cell signalling and the mevalonate pathway in cancer. Nat Rev Cancer 2016;16:718-31.

[154] Nguyen VT, Barozzi I, Faronato M, Lombardo Y, Steel JH, Patel N et al. Differential epigenetic reprogramming in response to specific endocrine therapies promotes cholesterol biosynthesis and cellular invasion. Nat Commun 2015;6:10044.

[155] Simigdala N, Gao Q, Pancholi S, Roberg-Larsen H, Zvelebil M, Ribas R et al. Cholesterol biosynthesis pathway as a novel mechanism of resistance to estrogen deprivation in estrogen receptor-positive breast cancer. Breast Cancer Res 2016;18:58.

[156] Gustbee E, Tryggvadottir H, Markkula A, Simonsson M, Nodin B, Jirstrom K et al. Tumorspecific expression of HMG-CoA reductase in a population-based cohort of breast cancer patients. BMC Clin Pathol 2015;15:8.

[157] Bjarnadottir O, Feldt M, Inasu M, Bendahl PO, Elebro K, Kimbung S et al. Statin use, HMGCR expression, and breast cancer survival - The Malmo Diet and Cancer Study. Sci Rep 2020;10:558.

[158] Borgquist S, Jogi A, Ponten F, Ryden L, Brennan DJ, Jirstrom K. Prognostic impact of tumour-specific HMG-CoA reductase expression in primary breast cancer. Breast Cancer Res 2008;10:R79.

[159] Brennan DJ, Laursen H, O'Connor DP, Borgquist S, Uhlen M, Gallagher WM et al. Tumorspecific HMG-CoA reductase expression in primary premenopausal breast cancer predicts response to tamoxifen. Breast Cancer Res 2011;13:R12.

[160] Brennan DJ, Brandstedt J, Rexhepaj E, Foley M, Ponten F, Uhlen M et al. Tumour-specific HMG-CoAR is an independent predictor of recurrence free survival in epithelial ovarian cancer. BMC Cancer 2010;10:125.

[161] Bengtsson E, Nerjovaj P, Wangefjord S, Nodin B, Eberhard J, Uhlen M et al. HMG-CoA reductase expression in primary colorectal cancer correlates with favourable clinicopathological characteristics and an improved clinical outcome. Diagn Pathol 2014;9:78. [162] Clendening JW, Pandyra A, Boutros PC, El Ghamrasni S, Khosravi F, Trentin GA et al. Dysregulation of the mevalonate pathway promotes transformation. Proc Natl Acad Sci U S A 2010;107:15051-6.

[163] Kimbung S, Lettiero B, Feldt M, Bosch A, Borgquist S. High expression of cholesterol biosynthesis genes is associated with resistance to statin treatment and inferior survival in breast cancer. Oncotarget 2016;7:59640-51.

[164] Cypriani B, Tabacik C, Descomps B, Crastes de Paulet A. Role of estrogen receptors and antiestrogen binding sites in an early effect of antiestrogens, the inhibition of cholesterol biosynthesis. J Steroid Biochem 1988;31:763-71.

[165] Gylling H, Mantyla E, Miettinen TA. Tamoxifen decreases serum cholesterol by inhibiting cholesterol synthesis. Atherosclerosis 1992;96:245-7.

[166] Gylling H, Pyrhonen S, Mantyla E, Maenpaa H, Kangas L, Miettinen TA. Tamoxifen and toremifene lower serum cholesterol by inhibition of $\Delta^{8}$-cholesterol conversion to lathosterol in women with breast cancer. J Clin Oncol 1995;13:2900-5.

[167] Sutherland RL, Murphy LC, San Foo M, Green MD, Whybourne AM, Krozowski ZS. Highaffinity anti-oestrogen binding site distinct from the oestrogen receptor. Nature 1980;288:2735.

[168] Kedjouar B, de Medina P, Oulad-Abdelghani M, Payre B, Silvente-Poirot S, Favre G et al. Molecular characterization of the microsomal tamoxifen binding site. J Biol Chem

2004;279:34048-61. 
[169] Suarez Y, Fernandez C, Gomez-Coronado D, Ferruelo AJ, Davalos A, Martinez-Botas J et al. Synergistic upregulation of low-density lipoprotein receptor activity by tamoxifen and lovastatin. Cardiovasc Res 2004;64:346-55.

[170] Cho SY, Kim JH, Paik YK. Cholesterol biosynthesis from lanosterol: differential inhibition of sterol delta 8-isomerase and other lanosterol-converting enzymes by tamoxifen. Mol Cells 1998;8:233-9.

[171] Holleran AL, Lindenthal B, Aldaghlas TA, Kelleher JK. Effect of tamoxifen on cholesterol synthesis in HepG2 cells and cultured rat hepatocytes. Metabolism 1998;47:1504-13.

[172] Poirot M, Silvente-Poirot S, Weichselbaum RR. Cholesterol metabolism and resistance to tamoxifen. Curr Opin Pharmacol 2012;12:683-9.

[173] Luu W, Hart-Smith G, Sharpe LJ, Brown AJ. The terminal enzymes of cholesterol synthesis, DHCR24 and DHCR7, interact physically and functionally. J Lipid Res 2015;56:888-97. [174] de Medina P, Payre B, Boubekeur N, Bertrand-Michel J, Terce F, Silvente-Poirot S et al. Ligands of the antiestrogen-binding site induce active cell death and autophagy in human breast cancer cells through the modulation of cholesterol metabolism. Cell Death Differ 2009;16:1372-84.

[175] Sola B, Poirot M, de Medina P, Bustany S, Marsaud V, Silvente-Poirot S et al. Antiestrogen-binding site ligands induce autophagy in myeloma cells that proceeds through alteration of cholesterol metabolism. Oncotarget 2013;4:911-22.

[176] Nes WD, Zhou W, Dennis AL, Li H, Jia Z, Keith RA et al. Purification, characterization and catalytic properties of human sterol 8-isomerase. Biochem J 2002;367:587-99.

[177] Long T, Hassan A, Thompson BM, McDonald JG, Wang J, Li X. Structural basis for human sterol isomerase in cholesterol biosynthesis and multidrug recognition. Nat Commun 2019;10:2452.

[178] Taton M, Benveniste P, Rahier A. Microsomal $\Delta^{8,14}$-sterol $\Delta^{14}$-reductase in higher plants. Characterization and inhibition by analogues of a presumptive carbocationic intermediate of the reduction reaction. Eur J Biochem 1989;185:605-14.

[179] Rahier A, Taton M. Sterol biosynthesis: strong inhibition of maize $\Delta^{5,7}$-sterol $\Delta^{7}$-reductase by novel 6 -aza- $B$-homosteroids and other analogs of a presumptive carbocationic intermediate of the reduction reaction. Biochemistry 1996;35:7069-76.

[180] Nes WD. Biosynthesis of cholesterol and other sterols. Chem Rev 2011;111:6423-51.

[181] Horton JD, Goldstein JL, Brown MS. SREBPs: activators of the complete program of cholesterol and fatty acid synthesis in the liver. J Clin Invest 2002;109:1125-31.

[182] Cerrato F, Fernandez-Suarez ME, Alonso R, Alonso M, Vazquez C, Pastor O et al. Clinically used selective oestrogen receptor modulators increase LDL receptor activity in primary human lymphocytes. Br J Pharmacol 2015;172:1379-94.

[183] Goldstein JL, Brown MS. The LDL receptor. Arterioscler Thromb Vasc Biol 2009;29:431-8.

[184] Ikonen E. Cellular cholesterol trafficking and compartmentalization. Nat Rev Mol Cell Biol 2008;9:125-38.

[185] Meng Y, Heybrock S, Neculai D, Saftig P. Cholesterol handling in lysosomes and beyond. Trends Cell Biol 2020;30:452-66.

[186] Brüning JC, Lingohr P, Gillette J, Hanstein B, Avci H, Krone W et al. Estrogen receptor- $\alpha$ and Sp1 interact in the induction of the low density lipoprotein-receptor. J Steroid Biochem Mol Biol 2003;86:113-21.

[187] Lemieux C, Gelinas Y, Lalonde J, Labrie F, Cianflone K, Deshaies Y. Hypolipidemic action of the SERM acolbifene is associated with decreased liver MTP and increased SR-BI and LDL receptors. J Lipid Res 2005;46:1285-94.

[188] Danel L, Menouni M, Cohen JH, Magaud JP, Lenoir G, Revillard JP et al. Distribution of androgen and estrogen receptors among lymphoid and haemopoietic cell lines. Leuk Res 1985;9:1373-8. 
[189] Insull W, Jr., Davidson MH, Kulkarni PM, Siddhanti S, Ciaccia AV, Keech CA. Effects of raloxifene and low-dose simvastatin coadministration on plasma lipids in postmenopausal women with primary hypercholesterolemia. Metabolism 2005;54:939-46.

[190] Fernandez-Suarez ME, Escola-Gil JC, Pastor O, Davalos A, Blanco-Vaca F, Lasuncion MA et al. Clinically used selective estrogen receptor modulators affect different steps of macrophagespecific reverse cholesterol transport. Sci Rep 2016;6:32105.

[191] Pentchev PG. Niemann-Pick C research from mouse to gene. Biochim Biophys Acta 2004;1685:3-7.

[192] Gallagher EJ, Zelenko Z, Neel BA, Antoniou IM, Rajan L, Kase N et al. Elevated tumor LDLR expression accelerates LDL cholesterol-mediated breast cancer growth in mouse models of hyperlipidemia. Oncogene 2017;36:6462-71.

[193] Rudling MJ, Stahle L, Peterson CO, Skoog L. Content of low density lipoprotein receptors in breast cancer tissue related to survival of patients. Br Med J (Clin Res Ed) 1986;292:580-2.

[194] Guo D, Reinitz F, Youssef M, Hong C, Nathanson D, Akhavan D et al. An LXR agonist promotes glioblastoma cell death through inhibition of an EGFR/AKT/SREBP-1/LDLRdependent pathway. Cancer Discov 2011;1:442-56.

[195] Villa GR, Hulce JJ, Zanca C, Bi J, Ikegami S, Cahill GL et al. An LXR-cholesterol axis creates a metabolic co-dependency for brain cancers. Cancer Cell 2016;30:683-93.

[196] Garcia-Bermudez J, Baudrier L, Bayraktar EC, Shen Y, La K, Guarecuco R et al. Squalene accumulation in cholesterol auxotrophic lymphomas prevents oxidative cell death. Nature 2019;567:118-22.

[197] Breiden B, Sandhoff K. Emerging mechanisms of drug-induced phospholipidosis. Biol Chem 2019;401:31-46.

[198] Altan N, Chen Y, Schindler M, Simon SM. Tamoxifen inhibits acidification in cells independent of the estrogen receptor. Proc Natl Acad Sci U S A 1999;96:4432-7.

[199] Lu F, Liang Q, Abi-Mosleh L, Das A, De Brabander JK, Goldstein JL et al. Identification of NPC1 as the target of U18666A, an inhibitor of lysosomal cholesterol export and Ebola infection. Elife 2015;4.

[200] Head SA, Shi WQ, Yang EJ, Nacev BA, Hong SY, Pasunooti KK et al. Simultaneous targeting of NPC1 and VDAC1 by itraconazole leads to synergistic inhibition of mTOR signaling and angiogenesis. ACS Chem Biol 2017;12:174-82.

[201] Lyu J, Yang EJ, Head SA, Ai N, Zhang B, Wu C et al. Astemizole inhibits mTOR signaling and angiogenesis by blocking cholesterol trafficking. Int J Biol Sci 2018;14:1175-85.

[202] Lyu J, Yang EJ, Head SA, Ai N, Zhang B, Wu C et al. Pharmacological blockade of cholesterol trafficking by cepharanthine in endothelial cells suppresses angiogenesis and tumor growth. Cancer Lett 2017;409:91-103.

[203] Cenedella RJ. Cholesterol synthesis inhibitor U18666A and the role of sterol metabolism and trafficking in numerous pathophysiological processes. Lipids 2009;44:477-87.

[204] Rabanal-Ruiz Y, Korolchuk VI. mTORC1 and Nutrient homeostasis: The central role of the lysosome. Int J Mol Sci 2018;19.

[205] Saxton RA, Sabatini DM. mTOR signaling in growth, metabolism, and disease. Cell 2017;168:960-76.

[206] Mossmann D, Park S, Hall MN. mTOR signalling and cellular metabolism are mutual determinants in cancer. Nat Rev Cancer 2018;18:744-57.

[207] Alayev A, Salamon RS, Berger SM, Schwartz NS, Cuesta R, Snyder RB et al. mTORC1 directly phosphorylates and activates ER $\alpha$ upon estrogen stimulation. Oncogene 2016;35:3535-43.

[208] Castellano BM, Thelen AM, Moldavski O, Feltes M, van der Welle RE, Mydock-McGrane L et al. Lysosomal cholesterol activates mTORC1 via an SLC38A9-Niemann-Pick C1 signaling complex. Science 2017;355:1306-11. 
[209] Lim CY, Davis OB, Shin HR, Zhang J, Berdan CA, Jiang X et al. ER-lysosome contacts enable cholesterol sensing by mTORC1 and drive aberrant growth signalling in Niemann-Pick type $C$. Nat Cell Biol 2019;21:1206-18.

[210] Shim JS, Li RJ, Lv J, Head SA, Yang EJ, Liu JO. Inhibition of angiogenesis by selective estrogen receptor modulators through blockade of cholesterol trafficking rather than estrogen receptor antagonism. Cancer Lett 2015;362:106-15.

[211] Xu J, Dang Y, Ren YR, Liu JO. Cholesterol trafficking is required for mTOR activation in endothelial cells. Proc Natl Acad Sci U S A 2010;107:4764-9.

[212] Chong CR, Xu J, Lu J, Bhat S, Sullivan DJ, Jr., Liu JO. Inhibition of angiogenesis by the antifungal drug itraconazole. ACS Chem Biol 2007;2:263-70.

[213] Karar J, Maity A. PI3K/AKT/mTOR pathway in angiogenesis. Front Mol Neurosci 2011;4:51.

[214] Blackwell KL, Haroon ZA, Shan S, Saito W, Broadwater G, Greenberg CS et al. Tamoxifen inhibits angiogenesis in estrogen receptor-negative animal models. Clin Cancer Res 2000;6:4359-64.

[215] Lyu J, Yang EJ, Shim JS. Cholesterol trafficking: An emerging therapeutic target for angiogenesis and Cancer. Cells 2019;8.

[216] Cheng X, Li J, Guo D. SCAP/SREBPs are central players in lipid metabolism and novel metabolic targets in cancer therapy. Curr Top Med Chem 2018;18:484-93.

[217] Chang TY, Li BL, Chang CC, Urano Y. Acyl-coenzyme A:cholesterol acyltransferases. Am J Physiol Endocrinol Metab 2009;297:E1-9.

[218] Allahverdian S, Chehroudi AC, McManus BM, Abraham T, Francis GA. Contribution of intimal smooth muscle cells to cholesterol accumulation and macrophage-like cells in human atherosclerosis. Circulation 2014;129:1551-9.

[219] Brown MS, Goldstein JL. Lipoprotein metabolism in the macrophage: implications for cholesterol deposition in atherosclerosis. Annu Rev Biochem 1983;52:223-61.

[220] Liscum L, Faust JR. Low density lipoprotein (LDL)-mediated suppression of cholesterol synthesis and LDL uptake is defective in Niemann-Pick type C fibroblasts. J Biol Chem 1987;262:17002-8.

[221] Pentchev PG, Kruth HS, Comly ME, Butler JD, Vanier MT, Wenger DA et al. Type C Niemann-Pick disease. A parallel loss of regulatory responses in both the uptake and esterification of low density lipoprotein-derived cholesterol in cultured fibroblasts. J Biol Chem 1986;261:16775-80.

[222] Liscum L, Faust JR. The intracellular transport of low density lipoprotein-derived cholesterol is inhibited in Chinese hamster ovary cells cultured with 3- $\beta$-[2-

(diethylamino)ethoxy]androst-5-en-17-one. J Biol Chem 1989;264:11796-806.

[223] de Medina P, Payre BL, Bernad J, Bosser I, Pipy B, Silvente-Poirot S et al. Tamoxifen is a potent inhibitor of cholesterol esterification and prevents the formation of foam cells. J Pharmacol Exp Ther 2004;308:1165-73.

[224] Geng F, Cheng X, Wu X, Yoo JY, Cheng C, Guo JY et al. Inhibition of SOAT1 suppresses glioblastoma growth via blocking SREBP-1-mediated lipogenesis. Clin Cancer Res 2016;22:5337-48.

[225] Li J, Gu D, Lee SS, Song B, Bandyopadhyay S, Chen S et al. Abrogating cholesterol esterification suppresses growth and metastasis of pancreatic cancer. Oncogene 2016;35:6378-88.

[226] de Gonzalo-Calvo D, Lopez-Vilaro L, Nasarre L, Perez-Olabarria M, Vazquez T, Escuin D et al. Intratumor cholesteryl ester accumulation is associated with human breast cancer proliferation and aggressive potential: a molecular and clinicopathological study. BMC Cancer 2015;15:460. 
[227] Yue S, Li J, Lee SY, Lee HJ, Shao T, Song B et al. Cholesteryl ester accumulation induced by PTEN loss and PI3K/AKT activation underlies human prostate cancer aggressiveness. Cell Metab 2014;19:393-406.

[228] Lee HJ, Li J, Vickman RE, Li J, Liu R, Durkes AC et al. Cholesterol esterification inhibition suppresses prostate cancer metastasis by impairing the $\mathrm{Wnt} / \mathrm{B}$-catenin pathway. Mol Cancer Res 2018;16:974-85.

[229] Bemlih S, Poirier MD, El Andaloussi A. Acyl-coenzyme A: cholesterol acyltransferase inhibitor Avasimibe affect survival and proliferation of glioma tumor cell lines. Cancer Biol Ther 2010;9:1025-32.

[230] LaPensee CR, Mann JE, Rainey WE, Crudo V, Hunt SW, 3rd, Hammer GD. ATR-101, a selective and potent inhibitor of acyl-CoA acyltransferase 1, induces apoptosis in H295R adrenocortical cells and in the adrenal cortex of dogs. Endocrinology 2016;157:1775-88. [231] Antalis CJ, Arnold T, Rasool T, Lee B, Buhman KK, Siddiqui RA. High ACAT1 expression in estrogen receptor negative basal-like breast cancer cells is associated with LDL-induced proliferation. Breast Cancer Res Treat 2010;122:661-70.

[232] Shen WJ, Azhar S, Kraemer FB. SR-B1: A unique multifunctional receptor for cholesterol influx and efflux. Annu Rev Physiol 2018;80:95-116.

[233] Linton MF, Tao H, Linton EF, Yancey PG. SR-BI: A multifunctional receptor in cholesterol homeostasis and atherosclerosis. Trends Endocrinol Metab 2017;28:461-72.

[234] Calvo D, Vega MA. Identification, primary structure, and distribution of CLA-1, a novel member of the CD36/LIMPII gene family. J Biol Chem 1993;268:18929-35.

[235] Calvo D, Gomez-Coronado D, Lasuncion MA, Vega MA. CLA-1 is an 85-kD plasma membrane glycoprotein that acts as a high-affinity receptor for both native (HDL, LDL, and VLDL) and modified (OxLDL and AcLDL) lipoproteins. Arterioscler Thromb Vasc Biol 1997;17:2341-9.

[236] Landschulz KT, Pathak RK, Rigotti A, Krieger M, Hobbs HH. Regulation of scavenger receptor, class $B$, type I, a high density lipoprotein receptor, in liver and steroidogenic tissues of the rat. J Clin Invest 1996;98:984-95.

[237] Cao WM, Murao K, Imachi H, Yu X, Abe H, Yamauchi A et al. A mutant high-density lipoprotein receptor inhibits proliferation of human breast cancer cells. Cancer Res 2004;64:1515-21.

[238] Danilo C, Gutierrez-Pajares JL, Mainieri MA, Mercier I, Lisanti MP, Frank PG. Scavenger receptor class $B$ type I regulates cellular cholesterol metabolism and cell signaling associated with breast cancer development. Breast Cancer Res 2013;15:R87.

[239] Liu YY, Lin SJ, Chen YY, Liu LN, Bao LB, Tang LQ et al. High-density lipoprotein cholesterol as a predictor of poor survival in patients with nasopharyngeal carcinoma. Oncotarget 2016;7:42978-87.

[240] Xu GH, Lou N, Shi HC, Xu YC, Ruan HL, Xiao W et al. Up-regulation of SR-BI promotes progression and serves as a prognostic biomarker in clear cell renal cell carcinoma. BMC Cancer 2018;18:88.

[241] Saddar S, Mineo C, Shaul PW. Signaling by the high-affinity HDL receptor scavenger receptor B type I. Arterioscler Thromb Vasc Biol 2010;30:144-50.

[242] Al-Jarallah A, Trigatti BL. A role for the scavenger receptor, class B type I in high density lipoprotein dependent activation of cellular signaling pathways. Biochim Biophys Acta 2010;1801:1239-48.

[243] Gutierrez-Pajares JL, Ben Hassen C, Chevalier S, Frank PG. SR-BI: Linking cholesterol and lipoprotein metabolism with breast and prostate cancer. Front Pharmacol 2016;7:338.

[244] Mooberry LK, Sabnis NA, Panchoo M, Nagarajan B, Lacko AG. Targeting the SR-B1 receptor as a gateway for cancer therapy and imaging. Front Pharmacol 2016;7:466.

[245] Hoekstra M, Sorci-Thomas M. Rediscovering scavenger receptor type BI: surprising new roles for the HDL receptor. Curr Opin Lipidol 2017;28:255-60. 
[246] Wang D, Huang J, Gui T, Yang Y, Feng T, Tzvetkov NT et al. SR-BI as a target of natural products and its significance in cancer. Semin Cancer Biol 2020. doi:

10.1016/j.semcancer.2019.12.025. Online ahead of print.

[247] Yuan B, Wu C, Wang X, Wang D, Liu H, Guo L et al. High scavenger receptor class B type I expression is related to tumor aggressiveness and poor prognosis in breast cancer. Tumour Biol 2016;37:3581-8.

[248] Feng H, Wang M, Wu C, Yu J, Wang D, Ma J et al. High scavenger receptor class B type I expression is related to tumor aggressiveness and poor prognosis in lung adenocarcinoma: $A$ STROBE compliant article. Medicine (Baltimore) 2018;97:e0203.

[249] Panchoo M, Lacko A. Scavenger receptor class B type 1 regulates neuroblastoma cell proliferation, migration and invasion. Biochem Biophys Res Commun 2018;495:614-20.

[250] Schorghofer D, Kinslechner K, Preitschopf A, Schutz B, Rohrl C, Hengstschlager M et al. The HDL receptor SR-BI is associated with human prostate cancer progression and plays a possible role in establishing androgen independence. Reprod Biol Endocrinol 2015;13:88. [251] Leon CG, Locke JA, Adomat HH, Etinger SL, Twiddy AL, Neumann RD et al. Alterations in cholesterol regulation contribute to the production of intratumoral androgens during progression to castration-resistant prostate cancer in a mouse xenograft model. Prostate 2010;70:390-400.

[252] Pussinen PJ, Karten B, Wintersperger A, Reicher H, McLean M, Malle E et al. The human breast carcinoma cell line HBL-100 acquires exogenous cholesterol from high-density lipoprotein via CLA-1 (CD-36 and LIMPII analogous 1)-mediated selective cholesteryl ester uptake. Biochem J 2000;349:559-66.

[253] Zheng Y, Liu Y, Jin H, Pan S, Qian Y, Huang C et al. Scavenger receptor B1 is a potential biomarker of human nasopharyngeal carcinoma and its growth is inhibited by HDL-mimetic nanoparticles. Theranostics 2013;3:477-86.

[254] Tan JT, Prosser HC, Vanags LZ, Monger SA, Ng MK, Bursill CA. High-density lipoproteins augment hypoxia-induced angiogenesis via regulation of post-translational modulation of hypoxia-inducible factor 1alpha. FASEB J 2014;28:206-17.

[255] Dong P, Xie T, Zhou X, Hu W, Chen Y, Duan Y et al. Induction of macrophage scavenger receptor type $\mathrm{BI}$ expression by tamoxifen and 4-hydroxytamoxifen. Atherosclerosis

2011;218:435-42.

[256] Noy R, Pollard JW. Tumor-associated macrophages: from mechanisms to therapy. Immunity 2014;41:49-61.

[257] Du XM, Kim MJ, Hou L, Le Goff W, Chapman MJ, Van Eck M et al. HDL particle size is a critical determinant of ABCA1-mediated macrophage cellular cholesterol export. Circ Res 2015;116:1133-42.

[258] Vedin LL, Lewandowski SA, Parini P, Gustafsson JA, Steffensen KR. The oxysterol receptor LXR inhibits proliferation of human breast cancer cells. Carcinogenesis 2009;30:575-9.

[259] Kaneko T, Kanno C, Ichikawa-Tomikawa N, Kashiwagi K, Yaginuma N, Ohkoshi C et al. Liver $\mathrm{X}$ receptor reduces proliferation of human oral cancer cells by promoting cholesterol efflux via up-regulation of ABCA1 expression. Oncotarget 2015;6:33345-57.

[260] El Roz A, Bard JM, Huvelin JM, Nazih H. LXR agonists and ABCG1-dependent cholesterol efflux in MCF-7 breast cancer cells: relation to proliferation and apoptosis. Anticancer Res 2012;32:3007-13.

[261] Wu Q, Ishikawa T, Sirianni R, Tang H, McDonald JG, Yuhanna IS et al. 27Hydroxycholesterol promotes cell-autonomous, ER-positive breast cancer growth. Cell Rep 2013;5:637-45.

[262] Frolov A, Zielinski SE, Crowley JR, Dudley-Rucker N, Schaffer JE, Ory DS. NPC1 and NPC2 regulate cellular cholesterol homeostasis through generation of low density lipoprotein cholesterol-derived oxysterols. J Biol Chem 2003;278:25517-25. 
[263] Bovenga F, Sabba C, Moschetta A. Uncoupling nuclear receptor LXR and cholesterol metabolism in cancer. Cell Metab 2015;21:517-26.

[264] Lin CY, Vedin LL, Steffensen KR. The emerging roles of liver X receptors and their ligands in cancer. Expert Opin Ther Targets 2016;20:61-71.

[265] Sharma B, Agnihotri N. Role of cholesterol homeostasis and its efflux pathways in cancer progression. J Steroid Biochem Mol Biol 2019;191:105377.

[266] Yun SH, Park MG, Kim YM, Roh MS, Park JI. Expression of chicken ovalbumin upstream promoter-transcription factor II and liver $\mathrm{X}$ receptor as prognostic indicators for human colorectal cancer. Oncol Lett 2017;14:4011-20.

[267] Melloni G, Muriana P, Bandiera A, Fontana R, Maggioni D, Russo V et al. Prognostic role of liver $X$ receptor-alpha in resected stage II and III non-small-cell lung cancer. Clin Respir J 2018;12:241-6.

[268] Sharma KL, Misra S, Kumar A, Mittal B. Association of liver X receptors (LXRs) genetic variants to gallbladder cancer susceptibility. Tumour Biol 2013;34:3959-66.

[269] Chuu CP, Hiipakka RA, Kokontis JM, Fukuchi J, Chen RY, Liao S. Inhibition of tumor growth and progression of $\mathrm{LNCaP}$ prostate cancer cells in athymic mice by androgen and liver $\mathrm{X}$ receptor agonist. Cancer Res 2006;66:6482-6.

[270] Nelson ER, Wardell SE, Jasper JS, Park S, Suchindran S, Howe MK et al. 27-

Hydroxycholesterol links hypercholesterolemia and breast cancer pathophysiology. Science 2013;342:1094-8.

[271] Pommier AJ, Alves G, Viennois E, Bernard S, Communal Y, Sion B et al. Liver X Receptor activation downregulates AKT survival signaling in lipid rafts and induces apoptosis of prostate cancer cells. Oncogene 2010;29:2712-23.

[272] Lo Sasso G, Bovenga F, Murzilli S, Salvatore L, Di Tullio G, Martelli N et al. Liver X receptors inhibit proliferation of human colorectal cancer cells and growth of intestinal tumors in mice. Gastroenterology 2013;144:1497-507, 507 e1-13.

[273] Gabitova L, Restifo D, Gorin A, Manocha K, Handorf E, Yang DH et al. Endogenous sterol metabolites regulate growth of EGFR/KRAS-dependent tumors via LXR. Cell Rep 2015;12:192738.

[274] Wan W, Hou Y, Wang K, Cheng Y, Pu X, Ye X. The LXR-623-induced long non-coding RNA LINC01125 suppresses the proliferation of breast cancer cells via PTEN/AKT/p53 signaling pathway. Cell Death Dis 2019;10:248.

[275] Hassan TS, Paniccia A, Russo V, Steffensen KR. LXR inhibits proliferation of human breast cancer cells through the PI3K-Akt pathway. Nuclear Receptor Research 2015;2.

[276] Gong H, Guo P, Zhai Y, Zhou J, Uppal H, Jarzynka MJ et al. Estrogen deprivation and inhibition of breast cancer growth in vivo through activation of the orphan nuclear receptor liver $X$ receptor. Mol Endocrinol 2007;21:1781-90.

[277] Smith B, Land H. Anticancer activity of the cholesterol exporter ABCA1 gene. Cell Rep 2012;2:580-90.

[278] Chou JL, Huang RL, Shay J, Chen LY, Lin SJ, Yan PS et al. Hypermethylation of the TGF-beta target, $A B C A 1$ is associated with poor prognosis in ovarian cancer patients. Clin Epigenetics $2015 ; 7: 1$.

[279] Schimanski S, Wild PJ, Treeck O, Horn F, Sigruener A, Rudolph C et al. Expression of the lipid transporters $A B C A 3$ and $A B C A 1$ is diminished in human breast cancer tissue. Horm Metab Res 2010;42:102-9.

[280] Moustafa MA, Ogino D, Nishimura M, Ueda N, Naito S, Furukawa M et al. Comparative analysis of ATP-binding cassette $(A B C)$ transporter gene expression levels in peripheral blood leukocytes and in liver with hepatocellular carcinoma. Cancer Sci 2004;95:530-6.

[281] Bi DP, Yin CH, Zhang XY, Yang NN, Xu JY. MiR-183 functions as an oncogene by targeting ABCA1 in colon cancer. Oncol Rep 2016;35:2873-9. 
[282] Yamauchi Y, Iwamoto N, Rogers MA, Abe-Dohmae S, Fujimoto T, Chang CC et al.

Deficiency in the lipid exporter ABCA1 impairs retrograde sterol movement and disrupts sterol sensing at the endoplasmic reticulum. J Biol Chem 2015;290:23464-77.

[283] Pan H, Zheng Y, Pan Q, Chen H, Chen F, Wu J et al. Expression of LXRbeta, ABCA1 and ABCG1 in human triplenegative breast cancer tissues. Oncol Rep 2019;42:1869-77.

[284] Fernandez LP, Ramos-Ruiz R, Herranz J, Martin-Hernandez R, Vargas T, Mendiola M et al. The transcriptional and mutational landscapes of lipid metabolism-related genes in colon cancer. Oncotarget 2018;9:5919-30.

[285] Aguirre-Portoles C, Feliu J, Reglero G, Ramirez de Molina A. ABCA1 overexpression worsens colorectal cancer prognosis by facilitating tumour growth and caveolin-1-dependent invasiveness, and these effects can be ameliorated using the BET inhibitor apabetalone. Mol Oncol 2018;12:1735-52.

[286] Sekine Y, Demosky SJ, Stonik JA, Furuya Y, Koike H, Suzuki K et al. High-density lipoprotein induces proliferation and migration of human prostate androgen-independent cancer cells by an ABCA1-dependent mechanism. Mol Cancer Res 2010;8:1284-94.

[287] Tian C, Huang D, Yu Y, Zhang J, Fang Q, Xie C. ABCG1 as a potential oncogene in lung cancer. Exp Ther Med 2017;13:3189-94.

[288] Chen YH, Cimino PJ, Luo J, Dahiya S, Gutmann DH. ABCG1 maintains high-grade glioma survival in vitro and in vivo. Oncotarget 2016;7:23416-24.

[289] Namba Y, Sogawa C, Okusha Y, Kawai H, Itagaki M, Ono K et al. Depletion of lipid efflux pump ABCG1 triggers the intracellular accumulation of extracellular vesicles and reduces aggregation and tumorigenesis of metastatic cancer cells. Front Oncol 2018;8:376.

[290] Villablanca EJ, Raccosta L, Zhou D, Fontana R, Maggioni D, Negro A et al. Tumormediated liver $\mathrm{X}$ receptor-alpha activation inhibits CC chemokine receptor-7 expression on dendritic cells and dampens antitumor responses. Nat Med 2010;16:98-105.

[291] Goossens P, Rodriguez-Vita J, Etzerodt A, Masse M, Rastoin O, Gouirand V et al. Membrane cholesterol efflux drives tumor-associated macrophage reprogramming and tumor progression. Cell Metab 2019;29:1376-89 e4.

[292] Zamanian-Daryoush M, Lindner DJ, DiDonato JA, Wagner M, Buffa J, Rayman P et al. Myeloid-specific genetic ablation of ATP-binding cassette transporter ABCA1 is protective against cancer. Oncotarget 2017;8:71965-80.

[293] Sag D, Cekic C, Wu R, Linden J, Hedrick CC. The cholesterol transporter ABCG1 links cholesterol homeostasis and tumour immunity. Nat Commun 2015;6:6354.

[294] Kloudova A, Guengerich FP, Soucek P. The role of oxysterols in human cancer. Trends Endocrinol Metab 2017;28:485-96.

[295] Silvente-Poirot S, Dalenc F, Poirot M. The effects of cholesterol-derived oncometabolites on nuclear receptor function in cancer. Cancer Res 2018;78:4803-8.

[296] Ma L, Nelson ER. Oxysterols and nuclear receptors. Mol Cell Endocrinol 2019;484:42-51.

[297] Segala G, de Medina P, Iuliano L, Zerbinati C, Paillasse MR, Noguer E et al. 5,6-Epoxy-

cholesterols contribute to the anticancer pharmacology of tamoxifen in breast cancer cells.

Biochem Pharmacol 2013;86:175-89.

[298] de Medina P, Paillasse MR, Segala G, Poirot M, Silvente-Poirot S. Identification and pharmacological characterization of cholesterol-5,6-epoxide hydrolase as a target for tamoxifen and AEBS ligands. Proc Natl Acad Sci U S A 2010;107:13520-5.

[299] Berrodin TJ, Shen Q, Quinet EM, Yudt MR, Freedman LP, Nagpal S. Identification of $5 \alpha$, $6 \alpha$-epoxycholesterol as a novel modulator of liver $\mathrm{X}$ receptor activity. Mol Pharmacol 2010;78:1046-58.

[300] Voisin M, de Medina P, Mallinger A, Dalenc F, Huc-Claustre E, Leignadier J et al. Identification of a tumor-promoter cholesterol metabolite in human breast cancers acting through the glucocorticoid receptor. Proc Natl Acad Sci U S A 2017;114:E9346-E55. 
[301] Kloudova-Spalenkova A, Ueng YF, Wei S, Kopeckova K, Peter Guengerich F, Soucek P. Plasma oxysterol levels in luminal subtype breast cancer patients are associated with clinical data. J Steroid Biochem Mol Biol 2020;197:105566.

[302] Lin CY, Huo C, Kuo LK, Hiipakka RA, Jones RB, Lin HP et al. Cholestane- $3 \beta, 5 \alpha, 6 \beta$-triol suppresses proliferation, migration, and invasion of human prostate cancer cells. PLoS One 2013;8:e65734.

[303] Poirot M, Silvente-Poirot S. The tumor-suppressor cholesterol metabolite, dendrogenin $A$, is a new class of LXR modulator activating lethal autophagy in cancers. Biochem Pharmacol 2018;153:75-81.

[304] de Medina P, Paillasse MR, Segala G, Voisin M, Mhamdi L, Dalenc F et al. Dendrogenin A arises from cholesterol and histamine metabolism and shows cell differentiation and antitumour properties. Nat Commun 2013;4:1840.

[305] Segala G, David M, de Medina P, Poirot MC, Serhan N, Vergez F et al. Dendrogenin A drives LXR to trigger lethal autophagy in cancers. Nat Commun 2017;8:1903.

[306] Russell DW. Oxysterol biosynthetic enzymes. Biochim Biophys Acta 2000;1529:126-35. [307] Nelson ER. The significance of cholesterol and its metabolite, 27-hydroxycholesterol in breast cancer. Mol Cell Endocrinol 2018;466:73-80.

[308] Karuna R, Holleboom AG, Motazacker MM, Kuivenhoven JA, Frikke-Schmidt R, TybjaergHansen $A$ et al. Plasma levels of 27-hydroxycholesterol in humans and mice with monogenic disturbances of high density lipoprotein metabolism. Atherosclerosis 2011;214:448-55.

[309] Babiker A, Diczfalusy U. Transport of side-chain oxidized oxysterols in the human circulation. Biochim Biophys Acta 1998;1392:333-9.

[310] Bjorkhem I. Do oxysterols control cholesterol homeostasis? J Clin Invest 2002;110:72530.

[311] Song BL, DeBose-Boyd RA. Ubiquitination of 3-hydroxy-3-methylglutaryl-CoA reductase in permeabilized cells mediated by cytosolic $\mathrm{E} 1$ and a putative membrane-bound ubiquitin ligase. J Biol Chem 2004;279:28798-806.

[312] Radhakrishnan A, Ikeda Y, Kwon HJ, Brown MS, Goldstein JL. Sterol-regulated transport of SREBPs from endoplasmic reticulum to Golgi: oxysterols block transport by binding to Insig. Proc Natl Acad Sci U S A 2007;104:6511-8.

[313] Umetani M, Domoto H, Gormley AK, Yuhanna IS, Cummins CL, Javitt NB et al. 27Hydroxycholesterol is an endogenous SERM that inhibits the cardiovascular effects of estrogen. Nat Med 2007;13:1185-92.

[314] DuSell CD, Umetani M, Shaul PW, Mangelsdorf DJ, McDonnell DP. 27-hydroxycholesterol is an endogenous selective estrogen receptor modulator. Mol Endocrinol 2008;22:65-77. [315] DuSell CD, Nelson ER, Wang X, Abdo J, Modder UI, Umetani M et al. The endogenous selective estrogen receptor modulator 27-hydroxycholesterol is a negative regulator of bone homeostasis. Endocrinology 2010;151:3675-85.

[316] Nelson ER, DuSell CD, Wang X, Howe MK, Evans G, Michalek RD et al. The oxysterol, 27-hydroxycholesterol, links cholesterol metabolism to bone homeostasis through its actions on the estrogen and liver X receptors. Endocrinology 2011;152:4691-705.

[317] Lappano R, Recchia AG, De Francesco EM, Angelone T, Cerra MC, Picard D et al. The cholesterol metabolite 25-hydroxycholesterol activates estrogen receptor $\alpha$-mediated signaling in cancer cells and in cardiomyocytes. PLoS One 2011;6:e16631.

[318] Marwarha G, Raza S, Hammer K, Ghribi O. 27-hydroxycholesterol: A novel player in molecular carcinogenesis of breast and prostate cancer. Chem Phys Lipids 2017;207:108-26.

[319] Raza S, Ohm JE, Dhasarathy A, Schommer J, Roche C, Hammer KD et al. The cholesterol metabolite 27-hydroxycholesterol regulates $\mathrm{p} 53$ activity and increases cell proliferation via MDM2 in breast cancer cells. Mol Cell Biochem 2015;410:187-95. 
[320] Baek AE, Yu YA, He S, Wardell SE, Chang CY, Kwon S et al. The cholesterol metabolite 27 hydroxycholesterol facilitates breast cancer metastasis through its actions on immune cells. Nat Commun 2017;8:864.

[321] He S, Nelson ER. 27-Hydroxycholesterol, an endogenous selective estrogen receptor modulator. Maturitas 2017;104:29-35.

[322] Shen Z, Zhu D, Liu J, Chen J, Liu Y, Hu C et al. 27-Hydroxycholesterol induces invasion and migration of breast cancer cells by increasing MMP9 and generating EMT through activation of STAT-3. Environ Toxicol Pharmacol 2017;51:1-8.

[323] Revilla G, Pons MP, Baila-Rueda L, Garcia-Leon A, Santos D, Cenarro A et al. Cholesterol and 27-hydroxycholesterol promote thyroid carcinoma aggressiveness. Sci Rep 2019;9:10260. [324] Liu L, Li MY, Xing Y, Wang XY, Wang Y. The oncogenic roles of 27-hydroxycholesterol in glioblastoma. Oncol Lett 2019;18:3623-9.

[325] Aryal B, Singh AK, Rotllan N, Price N, Fernandez-Hernando C. MicroRNAs and lipid metabolism. Curr Opin Lipidol 2017;28:273-80.

[326] Iorio MV, Croce CM. MicroRNA dysregulation in cancer: diagnostics, monitoring and therapeutics. A comprehensive review. EMBO Mol Med 2012;4:143-59. 


\section{Figure legends}

Figure 1. Scheme of the cholesterol biosynthesis pathway and enzymes inhibited by different molecules. Cholesterol biosynthesis from acetyl-CoA is depicted, as well as the branch to geranylgeranyl-diphosphate. The lanosterol-to-cholesterol pathway, which actually may proceed through two routes, the so-called Bloch pathway, which uses $\Delta^{24}$-unsaturated sterols, and the Kandutsch-Russell pathway, with side-chain saturated sterols, has been simplified. The Bloch pathway has been diverted at zymosterol and cholesten-7,24-dien-3 $\beta$-ol to show intermediate sterols that accumulate after treatment with inhibitors of interest. HMG-CoA, 3hydroxy-3-methylglutaryl-coenzyme A; FF-MAS, follicular fluid meiosis activating sterol; T-MAS, testicular meiosis activating sterol. Enzyme acronyms: ACAT2, acetyl-CoA acetyltransferase, cytosolic; HMGCS1, hydroxymethylglutaryl-CoA synthase, cytoplasmic; HMGCR, 3-hydroxy-3methylglutaryl-coenzyme A reductase; MVK, mevalonate kinase; PMVK, phosphomevalonate kinase; MVD, diphosphomevalonate decarboxylase; IDI1/2, isopentenyl-diphosphate $\Delta$-isomerase, isoforms 1 and 2; GGPS1, geranylgeranyl diphosphate synthase; FDPS, farnesyl diphosphate synthase; FDFT1, squalene synthase; SQLE, squalene monooxygenase; LSS, lanosterol synthase; CYP51A1, lanosterol 14 $\alpha$-demethylase; DHCR14 (LBR), $\Delta^{14}$-sterol reductase (lamin-B receptor); TM7SF2, $\Delta^{14}$-sterol reductase; SC4MOL, methylsterol monooxygenase 1; NSDHL, sterol-4 $\alpha$-carboxylate 3-dehydrogenase, decarboxylating; HSD17B7, 3-keto-steroid reductase; D8D7I (EBP), 3 $\beta$-hydroxysteroid- $\Delta^{8}, \Delta^{7}$-isomerase (emopamil-binding protein); DHCR24, $\Delta^{24}$-sterol reductase; SC5DL, lathosterol oxidase; DHCR7, 7-dehydrocholesterol reductase. 6-Fmv, 6-fluoromevalonate; SERMs, selective estrogen receptor modulators; TASIN, truncated APC selective inhibitors. Double arrows indicate several reactions catalyzed by different enzymes.

Figure 2. Effects of SERMs on cellular cholesterol metabolism and homeostasis. SERMs suppress endolysosomal cholesterol (C) trafficking and, moreover, cholesterol biosynthesis through inhibition of the AEBS enzymatic complex, thus inducing the accumulation of zymostenol (Zymo) and desmosterol (Desm). Consequently, the processing of the SREBP-2 precursor (pSREBP-2) to generate nuclear SREBP-2 (nSREBP-2) remains active, which results in LDLR overexpression, whereas LXR activation and subsequent expression of ABCA1 and ABCG1 in response to LDL are blunted. Induction of cholesterol esterification and ACAT-1 activity are also abrogated, as well as mTORC1 activation on the lysosomal surface. Inhibition of the AEBS together with the generation of reactive oxygen species (ROS) causes the accumulation of 5,6 -epoxycholesterols $(5,6 \alpha-E C$ and $5,6 \beta-E C)$, which cannot be successively converted to cholestane- $3 \beta, 5 \alpha, 6 \beta$-triol (CT) and 6-oxo-cholestan-3 $\beta, 5 \alpha$-diol (OCDO). Furthermore, SERMs increase SR-BI expression by an unknown mechanism. The principal effects of SERMs on the levels of the indicated sterols, proteins and MTORC1 are depicted with up or down arrows.

* Denotes ligand-mediated activation; P denotes phosphorylation; 5,6-ECS, 5,6aepoxycholesterol-3 $\beta$-sulfate; GR, glucocorticoid receptor; Hist, histamine. 


\section{Figure 1}

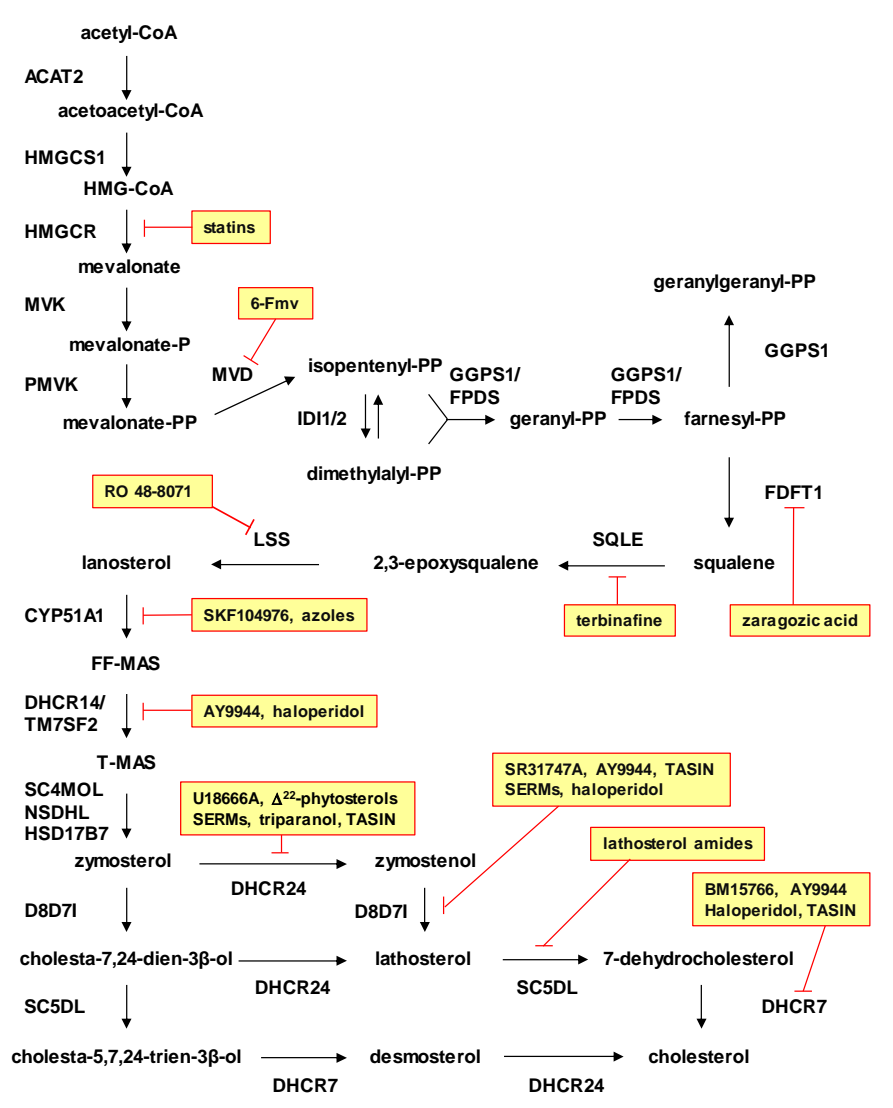


Figure 2

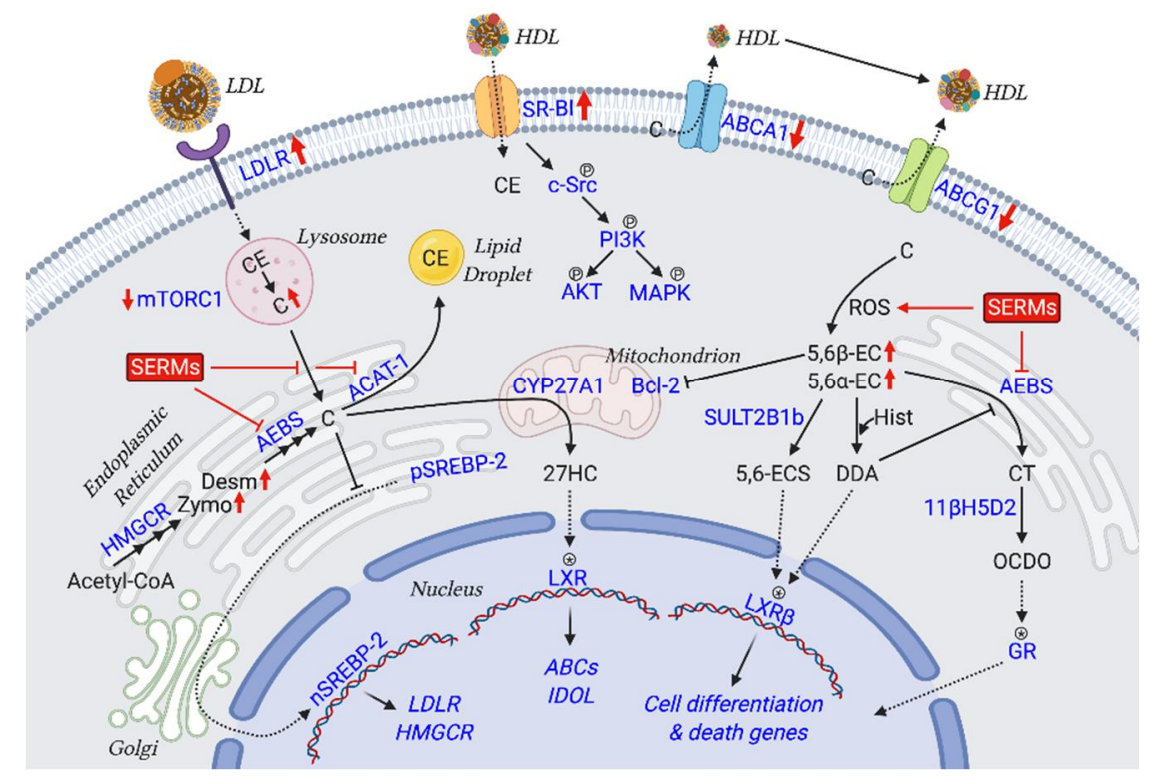

